\title{
Pooling Risk Among Countries
}

Jean Imbs and Paolo Mauro 



\title{
IMF Working Paper
}

\author{
Research Department
}

\section{Pooling Risk Among Countries}

\section{Prepared by Jean Imbs and Paolo Mauro ${ }^{1}$}

June 2007

\begin{abstract}
This Working Paper should not be reported as representing the views of the IMF. The views expressed in this Working Paper are those of the author(s) and do not necessarily represent those of the IMF or IMF policy. Working Papers describe research in progress by the author(s) and are published to elicit comments and to further debate.

In this paper, we identify the groups of countries where international risk-sharing opportunities are most attractive. We show that the bulk of risk-sharing gains can be achieved in groups consisting of as few as seven members, and that further marginal benefits quickly become negligible. For many such small groups, the welfare gains associated with risk sharing can amount to one order of magnitude larger than Lucas's classic calibration suggested for the United States, under similar assumptions on utility. Why do we not observe more arrangements of this type? Large welfare gains can only be achieved within groups where contracts are probably seen as relatively difficult to enforce. International diversification can thus yield substantial gains, but these may remain untapped owing to potential partners' weak institutional quality and a history of default on international obligations. Noting that existing risk sharing arrangements often have a regional dimension, we speculate that shared economic interests such as common trade may help sustain such arrangements, though risk-sharing gains are smaller when membership is constrained on a regional basis.
\end{abstract}

JEL Classification Numbers: E21, E32, E34, F41

Keywords: Risk Sharing, Diversification, Enforceability

Authors’ E-Mail Addresses: jimbs@unil.ch; pmauro@imf.org

\footnotetext{
${ }^{1}$ The first draft of this paper was written while Imbs was a resident scholar in the IMF's Research Department. We are grateful to Tamim Bayoumi, Mick Devereux, Michael Kremer, Raghuram Rajan, and Jaume Ventura for insightful suggestions; to Nicolas Metzger, José Romero, and especially Michael Callen for superb research assistance; and to Jean Salvati and especially Huigang Chen and Alin Mirastean for invaluable help in programming, computational support, and guidance to the computer science literature.
} 
Contents

Page

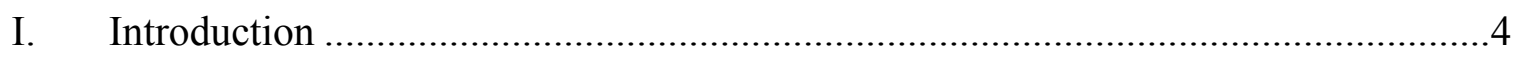

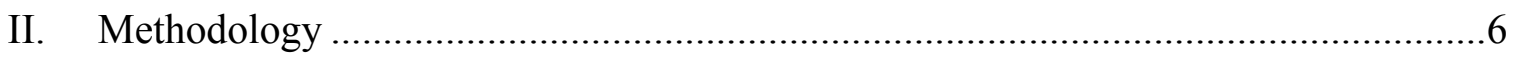

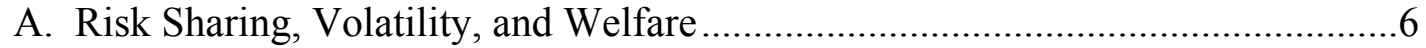

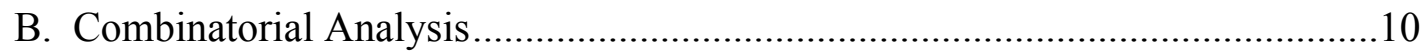

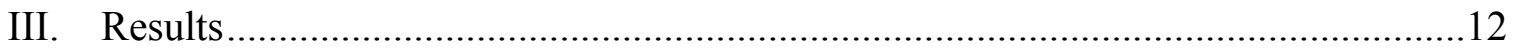

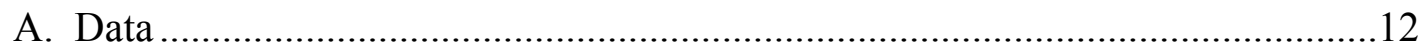

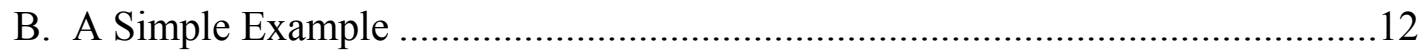

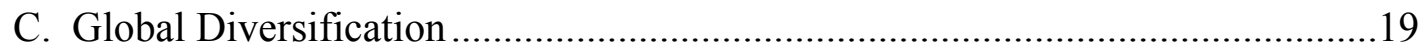

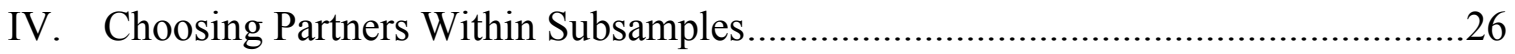

A. Level of Development and Country Size .....................................................28

B. Institutional Quality and Past Payment Record..............................................29

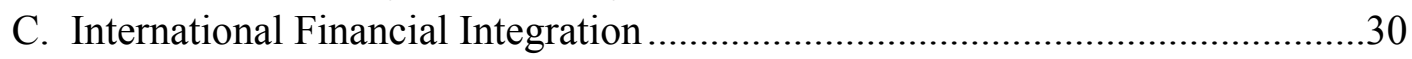

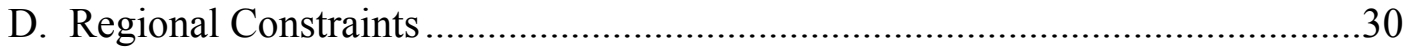

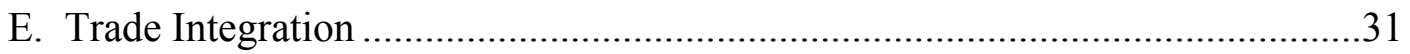

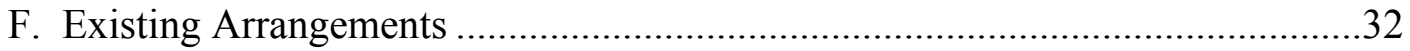

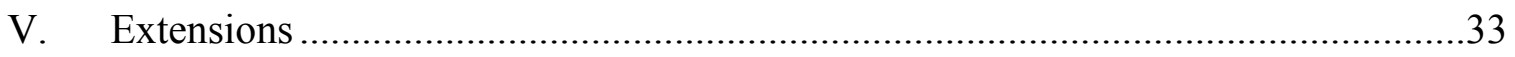

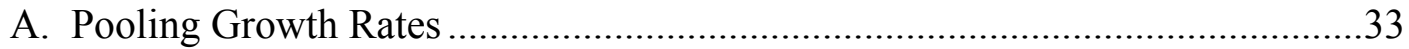

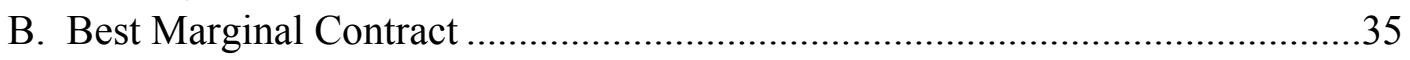

C. Liquidity-Crisis Based Criteria ............................................................... 37

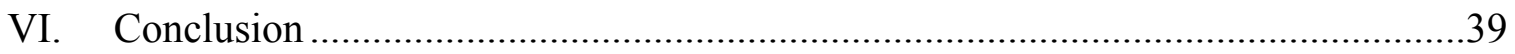

Tables:

1. Components Accounting for the Variance of the Best Pool of Seven Countries For Chile ................................................................................................... 17

2. Standard Deviation of Poolwide Growth—Best Pools Versus Best Stable Pools.......21

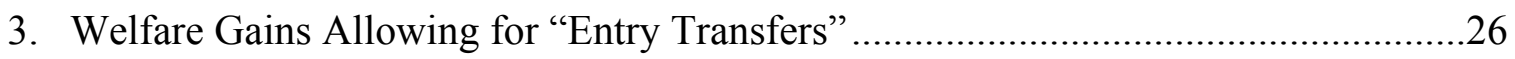

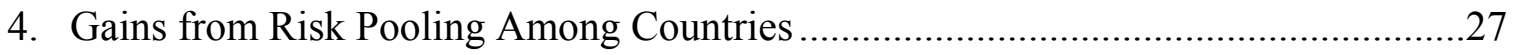

5. Poolwide Volatility for Selected Groups ..............................................................34

6. Welfare Gains Allowing for "Entry Transfers" and Differences in

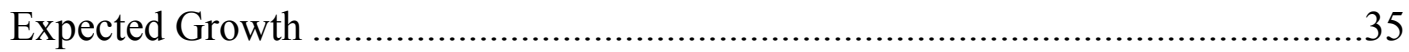

7. Frequency of Common Crises in Pools of Various Sizes, 1975-2004 ......................38 
Figures:

1. Chile: Benefits of Diversification Under Various Restrictions ...................................14

2 Components Accounting for Chile's Variance in the Best Pools of Each Size...........18

3. Is Chile's Minimum Volatility Pool Stable?..............................................................20

4. Lowest Poolwide Volatility Envelopes for Samples Constrained by Level

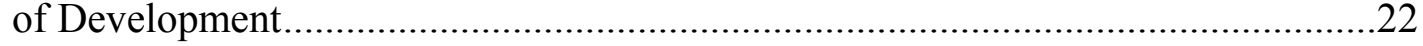

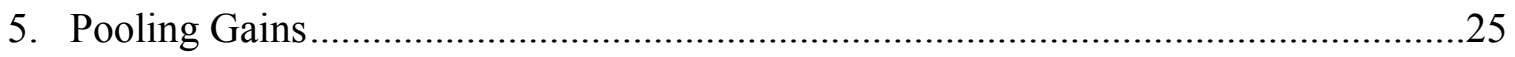

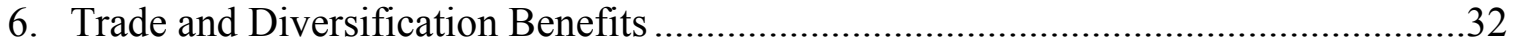

7. Standard Deviation of Arithmetic Mean Growth Rate .................................................36

Appendix: "Stable" Pools Based on Volatility Criterion...................................................41

Appendix Tables:

1. Country Samples

2. Lowest Standard Deviation of Poolwide Growth Choosing Pools Under

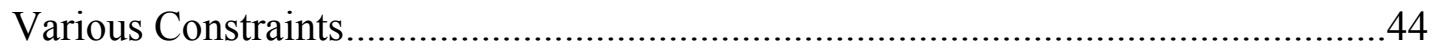

3. Welfare Gains for Different Groups of Countries Under Various Constraints .............45

Appendix Figure 1. Stable Groups for Fixed Pool Sizes ..................................................46

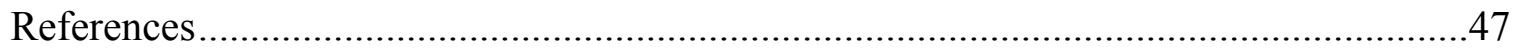




\section{INTRODUCTION}

Under perfect international risk sharing, country-specific risk is insured away as citizens hold and consume out of an identical portfolio of state-dependent assets. Full diversification entails payments going from booming economies into ones in recession, and requires an ability to monitor and enforce contractual arrangements. ${ }^{2}$ If monitoring and enforcement become difficult or costly as the number of countries involved increases, then the question of how to choose who to share risk with acquires key importance. Choosing a membership then involves a tradeoff between diversification benefits and monitoring costs, and may result in groups that involve a limited number of countries. This paper focuses on the benefits side, and empirically estimates risk diversification opportunities for all possible groups in a sample of 74 countries.

The relevance of the question is highlighted by the existence of a few schemes that indeed have sought to foster international sharing of macroeconomic risks within "clubs" (or "pools") consisting of a limited number of countries, rather than worldwide. These schemes include, for example, pooling arrangements for international reserves, such as the Chiang Mai initiative, the Latin American Reserve Fund (FLAR), or networks of bilateral swap arrangements among the G-10 in the 1960s-70s and among the European countries during the run up to the establishment of the Euro. ${ }^{3}$ Moreover, a number of schemes have been proposed, which seek to achieve international sharing of GDP risk among small groups of countries, including Robert C. Merton's $(1990,2000)$ suggestions regarding networks of bilateral swaps of GDP-linked income streams. ${ }^{4}$

Our main innovation consists in running a systematic search on all possible country groupings, using the variance-covariance matrix for output growth rates observed in standard international data for 74 countries at various levels of economic and financial development. We rely on an algorithm that makes it possible to draw up an exhaustive inventory of potential income insurance opportunities and to isolate the specific country groupings that minimize poolwide output growth volatility or maximize welfare diversification gains, for any possible pool size.

We find that pooling risk among countries can deliver sizable welfare gains. Indeed, substantial gains can be obtained in pools consisting of a handful of countries, and marginal gains decline

\footnotetext{
${ }^{2}$ On the implications of imperfect contract enforcement for the extent of feasible risk sharing, the business cycle, and the ability to reproduce otherwise puzzling features of the data, see for instance Kehoe and Perri (2002) and Kocherlakota (1996).

${ }^{3}$ More generally, currency and trade unions have also been shown to lead to greater international financial integration among their member countries, so that such unions could also be loosely seen as a way in which groups of countries have moved toward greater mutual risk sharing.

${ }^{4}$ On FLAR, see Eichengreen (2006) and www.flar.net; on the Chiang Mai initiative, see Park and Wang (2005), and http://aric.adb.org; on the earlier European experience, see Eichengreen and Wyplosz (1993). On sharing of GDP risks more generally see Shiller (1993); and Borensztein and Mauro (2004) for a review of the literature.
} 
quickly for groups beyond six or seven members. We find that many small pools - not surprisingly, involving relatively volatile economies - yield risk-sharing gains more than ten times what Lucas found for the United States, even though we use a similar theoretical framework. ${ }^{5}$ But if large welfare gains can be attained by pooling with a few other countries, why do these arrangements not emerge spontaneously more often? We show that the largest gains are attained by pooling together heterogeneous economies, in terms of business cycles characteristics, but also institutional quality, income level, and geographic location. Moreover, we show that potential diversification gains are far smaller when pools are formed within the sub-sample of countries characterized by high institutional quality and an unblemished payment record. We conjecture that enforcement may be more difficult for heterogeneous groupings, or for groupings that include countries whose institutional quality and perceived creditworthiness are lower.

Welfare gains are on average considerably lower when pools are constrained to be formed within a particular region or a given income category. Nevertheless, sizable welfare gains are often attainable through small pools of countries within a region, particularly when such pools include some countries whose perceived international creditworthiness is relatively low. In addition, the few pooling arrangements observed in practice often involve a regional element, perhaps reflecting cultural and political ties, trade linkages, or a mutual interest in each other's economic performance, including a desire to avoid crises in neighboring countries. This leads us to conjecture that the positive impact of trade linkages for contract enforceability in international risk-sharing may in some cases be more important than their negative impact on diversification opportunities. ${ }^{6} \mathrm{We}$ also estimate the risk-sharing benefits provided by existing reserve-pooling arrangements or free trade areas, and compare them with the benefits that could be provided by pools of similar size chosen in an unconstrained manner from the whole sample. The results are consistent with the view that contract enforceability is an important consideration.

This study is closely related to three well developed strands of the literature. First, our work builds on the rich literature that evaluates the gains from international risk sharing (see, for example, Cole and Obstfeld, 1991; Tesar, 1993; Lewis, 1996; van Wincoop, 1999; Athanasoulis and van Wincoop, 2000; and Sørensen and others, 2006). In particular, our welfare analysis is largely based on Lewis (2000) and Obstfeld (1994), though we focus on the relative magnitude of the risk-sharing opportunities provided by different groupings, rather than the absolute size of the potential gains from risk sharing. Second, an important ingredient in our framework relates to the international comovement of macroeconomic variables, the object of a large and

\footnotetext{
${ }^{5}$ Pallage and Robe (2002) show that the welfare cost of economic fluctuations is far larger in developing countries than in advanced economies. We go one step further, and investigate how quickly these gains accrue as the number of participants increases; moreover, we estimate the gains for vast numbers of possible country groupings.

${ }^{6}$ Our results are consistent with previous findings that trading partners tend to display more positively correlated business cycles (see, for example, Frankel and Rose, 1999).
} 
important empirical literature (including Backus, Kehoe and Kydland, 1994; Kehoe and Perri, 2002; Imbs, 2004; and Baxter and Kouparitsas, 2005). Third, any study on the relative desirability of different country groupings is related to the vast literature on optimum currency areas, going back to Mundell's (1961) seminal work, and more recently including Bayoumi and Eichengreen (1994; 1998), Alesina and Barro (2002), and Alesina, Barro, and Tenreyro (2003). At the same time, optimal pools of countries from a risk sharing point of view are almost certain not to coincide with optimal currency areas. ${ }^{7}$

The paper is organized as follows. Section II presents a refresher on the virtues of international risk sharing in theory, and outlines how we handle the combinatorial problem. Section III presents our general results on the potential for risk sharing gains in the sample of countries for which we have data. In Section IV, we estimate the extent to which the potential for risk sharing is reduced when countries can only choose their partners within a constrained universe: we focus, for example, on regional constraints, and on the need for countries to have sufficiently strong institutional quality in order to be trusted. Section V presents extensions, including an analysis of the frequency of common crises within various pools. Section VI concludes.

\section{Methodology}

In this section we first go through a quick refresher of the theory underpinning the welfare gains resulting from risk sharing. We then discuss the algorithms involved in our search for optimal pools of countries.

\section{A. Risk-Sharing, Volatility, and Welfare}

We are interested in the behavior of income and consumption for the countries that are members of a "pool," which we define as a group of countries that engage in complete risk sharing with each other. A standard assumption is that under complete markets each country issues and trades claims on its uncertain future output. ${ }^{8}$ As is well known, each country then consumes a fixed share of aggregate output, given by the country's share in the aggregate long-run present discounted value of future poolwide output (see, for example, Obstfeld and Rogoff, 1996). For our purposes, the key implication from this setup is that, in each period, the growth rate of consumption for any country in the pool will be the same as the growth rate of aggregate income for the pool, and will thus fluctuate along with uninsurable poolwide risk. This

\footnotetext{
${ }^{7}$ Historically, schemes to pool international reserves have often emerged - most notably in the case of the European countries - in a broader context of efforts to establish the conditions for common currencies. However, highly correlated shocks, which militate in favor of a common currency area, reduce diversification opportunities and thus the appeal of pooling arrangements.

${ }^{8}$ These claims pay a share of a country's future output, regardless of the state of nature; their payment streams can be interpreted as mimicking a mutual fund that owns the totality of a country's productive unit. The same results hold with a full set of Arrow-Debreu securities (which provide a payment in a given state of nature) or as the result of optimization by a benevolent social planner.
} 
underpins our focus on the standard deviation of the growth rate of poolwide GDP, and its comparison with the volatility of individual country output.'

Concretely, two types of arrangements could implement risk sharing consistent with this setup. Under the first, countries in the pool could issue claims on their output as proposed by Shiller (1993). However, we would then need to require that only residents of countries in the pool be able to trade such securities, which implies the need for related capital controls vis-à-vis nonmembers. The second type of arrangement would consist of GDP swaps, along the lines proposed by Merton $(1990,2000)$, either as a network of bilateral swaps, or as swaps intermediated by a central entity for the pool. Under the swaps, each period, each country would pay the others the net difference between its current output and its share in poolwide output (as warranted by its long-run share of poolwide output or wealth). ${ }^{10}$ There would be no need for capital controls: participation in the network of swaps would define the pool; a possible feature of a pool might also be that all participants would have to agree to additional bilateral swaps with non-members.

Under either arrangement, booming economies might have an incentive to default on their commitment to pay part of their income to foreign holders of their securities. The paper seeks to quantify the benefits of risk diversification, and thus does not focus on the costs of default. But if preventing default entails costly monitoring and/or enforcement, which may increase in the number of participants to an insurance scheme, then a second best may obtain, where sharing risk is done optimally among a few countries. Here, we investigate how the benefits of international risk sharing change with the number of countries involved.

We rely on a well-known framework largely based on Lewis (2000) and similar to Obstfeld (1994). ${ }^{11}$ We draw on the Epstein and Zin (1989) utility function, and assume that $C_{t}$ is lognormally distributed:

$U_{t}=\left\{C_{t}^{1-\theta}+\beta\left[E_{t}\left(U_{t+1}^{1-\gamma}\right)\right]^{(1-\theta) /(1-\gamma)}\right\}^{1 /(1-\theta)}$ and $c_{t}=c_{t-1}+\mu-\frac{1}{2} \sigma^{2}+\varepsilon_{t} \quad$ with $\varepsilon_{t} \sim N\left(0, \sigma^{2}\right)$

\footnotetext{
${ }^{9}$ The results are broadly similar when we use the volatility of individual country consumption (not reported for the sake of brevity).

${ }^{10}$ If expected growth rates differ across participant countries, this will be reflected in their shares of poolwide aggregate output under the contract.

${ }^{11}$ We thus abstract from non tradability and non separability in utility, and from the possible impact of uncertainty on growth. These refinements tend to boost the welfare implications of a given amount of risk sharing, and we conjecture that the same would occur in our setup. In a related vein, Barro (2007) relies on the possibility of large, disastrous events to derive much larger welfare costs of business cycles fluctuations than originally measured by Lucas. We find substantial welfare effects, despite the relative simplicity of the framework adopted here.
} 
where $c=\ln (C) ; 0<\beta<1$ denotes the subjective discount rate, $\gamma \geq 0$ is the coefficient of relative risk aversion, and $\theta$ is the inverse of the elasticity of intertemporal substitution in consumption.

As shown in Lewis (2000), welfare for the representative individual in country $j$ at time $t=0$ is given by:

$$
U_{0}^{j}=C_{0}^{j}\left\{1-\beta \exp \left[(1-\theta)\left(\mu_{j}-\frac{1}{2} \gamma \sigma_{j}^{2}\right)\right]\right\}^{-(1 /(1-\theta))}
$$

The welfare gain for moving from autarchy to pooling is expressed as the permanent percent increase in annual consumption in country $j$ under autarchy, $\delta^{j}$, that would make the representative individual just as well off as under pooling:

$$
\begin{gathered}
U\left[C_{0}^{j}\left(1+\delta^{j}\right), \mu_{j}, \sigma_{j}\right]=U\left[\underline{C}_{0}, \underline{\mu}, \underline{\sigma}\right], \text { that is, } \\
\delta^{j}=\frac{\underline{C}_{0}}{C_{0}^{j}} \frac{\left\{1-\beta \exp \left[(1-\theta)\left(\underline{\mu}-\frac{1}{2} \gamma \underline{\sigma}^{2}\right)\right]\right\}^{-(1 /(1-\theta))}}{\left\{1-\beta \exp \left[(1-\theta)\left(\mu_{j}-\frac{1}{2} \gamma \sigma_{j}^{2}\right)\right]\right\}^{-(1 /(1-\theta))}-1}
\end{gathered}
$$

The welfare gains from risk sharing depend on three factors. First, the difference between individual and poolwide volatilities, $\sigma_{j}$ and $\underline{\sigma}$, respectively. Second, the difference between growth rates within and without the pool, $\underline{\mu}$ and $\mu_{j}$, respectively. Third, the difference between initial consumption in autarchy, $C_{0}{ }^{j}$, and consumption in the pool, $\underline{C}_{0}$. This last difference reflects a (positive or negative) "entry transfer" in terms of initial consumption that country $j$ may pay other members for being allowed into the pool. ${ }^{12}$

Solving for entry transfers, Lewis (2000) shows that

$$
\frac{\underline{C}_{0}}{C_{0}^{j}}=\frac{H}{\exp \left(\underline{\mu}-\frac{1}{2} \gamma \underline{\sigma}^{2}\right)} \frac{1-\beta \exp \left[(1-\theta)\left(\underline{\mu}-\frac{1}{2} \gamma \underline{\sigma}^{2}\right)\right]}{1-\beta \exp \left[-\theta\left(\underline{\mu}-\frac{1}{2} \gamma \underline{\sigma}^{2}\right)\right] H}
$$

\footnotetext{
${ }^{12}$ We use the term "entry transfers" as shorthand. These transfers could take place later in the life of the contract. More important, the optimal (renegotiation-proof) contract would likely allow the share of poolwide output accruing to country $j$ to change during the life of the contract, in response to updated information regarding country $j$ 's long-term expected growth, volatility, and correlation with poolwide output.
} 
where $H=\operatorname{cov}\left(\varepsilon_{j}, \underline{\varepsilon}\right)$ reflects the desirability of country $j$ from the standpoint of the pool's hedging motive. Countries characterized by low (or negative) covariance with the pool will be more likely to receive a net transfer at the beginning of the arrangement $\left(C_{0}^{j}>\underline{C}_{0}\right)$. Conversely, countries whose output covaries strongly with poolwide output will be more likely to make a net payment in order to join the pool (that is, $C_{0}^{j}<\underline{C}_{0}$ ).

In what follows, we compare how countries fare individually and under pooling, using four main approaches. First, we report the standard deviation of the growth rate for individual country income and poolwide income. This simple approach conveys most of the key economic intuition. Second, moving to welfare, we consider the case where $\underline{\mu}=\mu_{j}$ (that is, expected growth is the same for all countries) and $C_{0}{ }^{j}=\underline{C}_{0}$ (that is, abstracting from entry transfers). These simplifying assumptions make it possible to focus narrowly on the welfare implications of the fall in volatility associated with pooling, and follow directly from Obstfeld (1994), where the emphasis is on the implications of reducing or eliminating volatility, rather than on trade in financial assets. Under this approach, welfare is a monotonic, non-linear transformation of the volatility of the growth rate. Thus, all results on the relative desirability of various pools, based purely on the motive of diversifying volatility, carry through exactly under this simple extension to welfare. Third, we report welfare allowing for entry transfers. More specifically, we compute total welfare gains as the income-weighted sum of $\delta_{j}$ across the membership, expressed as a share of the initial income of the relevant (sub-)universe of countries. Fourth and finally, in Section V.A we relax the assumption that growth rates are the same for all countries, and project $\underline{\mu}$ and $\mu_{j}$ using past observed growth rates. The paper thus follows a variety of alternative approaches, and does so for two reasons. First, we aim to provide a transparent presentation of where the gains are coming from. Second, and perhaps more important, views may differ regarding the realism of the various components of a risk sharing contract, e.g. the market determination of entry transfers, or the provision of insurance against differences in long-run growth as opposed to temporary fluctuations.

As is well known, the link between welfare and volatility depends on some crucial properties of the process generating uncertainty: in particular, insurance against permanent shocks has more value than against temporary ones (see, for instance, Obstfeld, 1994). We assume throughout the paper that GDP and consumption follow a random walk. This is not crucial to our purpose, and the assumption is only maintained so that we can decompose poolwide variances into meaningful elements (Section III.B). ${ }^{13}$ In alternative estimates, we ran our search algorithm under the assumption of trend stationarity. The results (not reported for the sake of brevity) were similar in terms of the general shape of minimum variance envelopes for the various country groupings. Under the alternative assumption of trend stationarity, measured uncertainty

\footnotetext{
${ }^{13}$ Under trend stationarity, the variance of the poolwide residual is not the variance of a sum of each member country's residual, and the difference between the two has no reason to be negligible.
} 
is higher, but the welfare costs of fluctuations are smaller for a given level of uncertainty. ${ }^{14}$ These two effects approximately offset one another. ${ }^{15}$ Therefore, the key simplification for our purposes is that the same type of process (either stationary or random walk) applies to all countries - an assumption that may prove difficult to invalidate, given the weakness of standard unit root tests. ${ }^{16}$

\section{B. Combinatorial Analysis}

Searching for pools of countries that yield the lowest possible variance of the growth rate of aggregate (poolwide) GDP is not straightforward, in light of the vast number of possible combinations of countries. We consider the $N$ countries in our sample individually, then all of their possible combinations 2 countries at a time (which equals $C_{2}^{N}$ ), then 3 at a time (which

equals $\left.C_{3}^{N}\right)$, and so on, where $C_{p}^{N}=\frac{N !}{p !(N-p) !}$. The total number of pools is $\sum_{p=1}^{N} C_{p}^{N}=2^{N}-1$,

which quickly reaches astronomical levels as $N$ rises. ${ }^{17}$

Using a computational algorithm whose details are provided in the Web Technical Appendix (available at www.imf.org), we are able to analyze all possible combinations for any pool size within a universe of 31 countries $\left(2^{31}=2.1\right.$ billion combinations). This algorithm can easily handle, for example, the universe of 26 emerging market countries-about 67 million combinations). However, when the universe consists of all 74 countries in our sample, the same algorithm only allows us to analyze all combinations of pools of size $7\left(C_{7}^{74}=1.8\right.$ billion) or

\footnotetext{
${ }^{14}$ If GDP truly has a unit root, the detrended residual will have explosive variance. If GDP is truly trend stationary, the variance of GDP growth will be lower than true residual variance. In both cases, measured volatility is higher when assuming trend stationarity.

${ }^{15}$ As is well known from Lucas' (1987) seminal paper, under trend stationarity, the welfare costs of fluctuations are approximately given by $\frac{1}{2} \gamma \sigma^{2}$, where $\gamma$ is the coefficient of risk aversion and $\sigma^{2}$ denotes the variance of residual uncertainty.

${ }^{16}$ Dezhbakhsh and Levy (2003) use frequency analysis to investigate the cross-section of spectra followed by GDP growth rates. They find substantial heterogeneity, but are unable to point to a key determining factor. Aguiar and Gopinath (2006) suggest that the random walk assumption may be more appropriate for emerging markets than for advanced countries.

${ }^{17}$ As the reader may remember, the integers in the $N$-th row in Pascal's (or Tartaglia's) triangle represent the number of possible combinations of $N$ objects taken 0 at a time, 1 at a time, 2 at a time, ...and $N$ at a time; the sum of the integers in the $N$-th row is $2^{N}$.
} 
less. (Or of size 67 or more, because $C_{p}^{N}=C_{N-p}^{N}$ ). Beyond that, we need to resort to an approximate algorithm. ${ }^{18}$

\section{Approximation method for large samples}

For searches involving group sizes where examining the full list of possible combinations exceeds the computing power of any readily available processor, we implement recursive searches. ${ }^{19}$ We first analyze all possible combinations up to the maximum pool size where this is feasible through an exhaustive search - in our case, all pools of size 7 drawn from the universe of 74 countries. We save not only the best pool of size 7, but also the best $W$ pools of size 7 that include each of the $N$ countries in the universe under consideration. In our baseline results, we use $W=1351$ (74 times 1351 is just below 100,000).

For each of these $W \cdot N$ "seed" pools, we analyze all pools that include the existing members, plus one of the $(N-p)$ remaining countries. Among these, we find the best pool of size 8 (as well as the $W \cdot N$ best new "seed" pools of size 8 ), and we iterate the procedure. Note that although there is a recursive aspect to this procedure, the fact that at each stage we consider the best $W$ pools for each of the $N$ countries gives plenty of opportunities for countries that are in the best pool of a given size to drop out when we move to the next pool size.

We have verified the reliability of this approximation in four different ways. First, for a number of the cases where it is possible to run exhaustive searches, we have found that the results are exactly the same as those obtained when the approximation procedure starts at pool sizes as low as 1 or 2 (rather than 7 as in the example above). Second, we have experimented with different values for $W$, as low as 2 , and have found systematically the same results as with $W=1351$. Third, for each pool size $p$, we have checked large numbers of random samples of countries. ${ }^{20}$ We have not found any instance in which a randomly identified pool was preferable to those identified as the best through the approximation procedure. Fourth, we have run exhaustive searches for all possible combinations of 67 (or more) countries selected amongst 74. Again, we

\footnotetext{
${ }^{18}$ When $N=74$, the total number of groups increases to $2^{74}=1.9 \times 10^{22}$, too large for existing computing power: for each group, one needs to sum the GDP levels for all countries in the pool, to compute an aggregate growth rate and the corresponding standard deviation. Even if each operation took a nanosecond to complete, running an exhaustive search over all possible pools amongst 74 countries would take hundreds of centuries.

${ }^{19}$ Combinatorial problems similar to those we are tackling are well known, and indeed the object of a large literature in computer sciences revolving around the so-called "Traveling Salesman" problem. Well-established methods can approximate the exact solution to that problem. Unfortunately, however, to our knowledge none can be applied to our baseline setup. For instance, Han, Ye and Zhang (2002) propose an approximation algorithm that could be applied to minimize the variance of a sum; but we minimize the variance of a weighted sum, where the weights themselves depend on the group membership. We use the Han, Ye and Zhang (2002) approximation algorithm in our "best marginal contract" exercise (Section V.B), which involves an unweighted average.

${ }^{20}$ This is a meaningful exercise up to, say, pool size 10, but is less revealing at larger pool sizes, where the proportion of random draws that can be analyzed becomes a minute fraction of all possible combinations.
} 
have found the same optimal pools as those obtained by running the approximation procedure throughout.

\section{RESULTS}

In this section we describe our dataset and present our results. We first build intuition through a simple, single country example. We then present the results pertaining to a "global envelope" of the groupings that achieve maximal risk sharing gains, for all group sizes.

\section{A. Data}

Data on yearly real gross domestic product and consumption, evaluated in purchasing power parity (PPP) U.S. dollars, for the period 1974-2004 are drawn from the World Bank's World Development Indicators. ${ }^{21}$ This yields a sample of 25 advanced countries, 26 emerging market countries, and 23 developing countries with complete coverage and data of reasonable quality. (The full country list is provided in Appendix Table 1). Advanced countries are defined as in the International Monetary Fund's World Economic Outlook. The remaining countries are considered emerging if they are included in either the stock-market-based International Financial Corporation's Major Index (2005), or JPMorgan's EMBI Global Index (2005), which includes countries that issue bonds on international markets. The remaining countries are classified as developing.

Throughout the paper, in line with the bulk of the literature on international risk sharing, we assume that PPP holds. ${ }^{22}$ To compute trade integration, the data on exports (in U.S. dollars at current prices) are drawn from the IMF's Direction of Trade Statistics, and the data on GDP (in U.S. dollars at current prices) are from the IMF's World Economic Outlook database.

\section{B. A Simple Example}

To develop intuition, we begin by asking what pools of countries minimize risk from the standpoint of an individual country, chosen as an example to illustrate the analytical approach. ${ }^{23}$

\footnotetext{
${ }^{21}$ Compared with the widely used Penn World Tables (PWT), the World Bank data base has similar-quality (in fact, usually identical) information, but provides PPP-adjusted data until 2004 rather than 2000. We cross-checked the two data bases over the period covered by both, and are confident that the results would be largely unaffected if we used the PWT.

${ }^{22}$ This corresponds to the notion that risk sharing is contracted on a pre-agreed exchange rate, possibly one that is expected to prevail in the long run. While standard, this is an important assumption: previous studies (for example, Backus and Smith, 1993; and Ravn, 2001) have established that real exchange rate fluctuations worsen the case for international risk sharing. Indeed, GDP data at market exchange rates would imply far higher volatility — harder to hedge through international risk sharing.

${ }^{23}$ We first focus on diversification gains. We introduce entry transfers in the next section, concerned with welfare gains in the universe of countries.
} 
We work through the case of Chile, which is viewed by international investors as a relatively safe emerging market (as evidenced by relatively low sovereign spreads). Chile is not participating in existing or prospective reserve-pooling arrangements and its economy is not overwhelmingly linked to a single or a few other countries. The general pattern of results holds for all other countries, as will become apparent in the next section.

For each pool size, Figure 1 plots the standard deviation of the growth rate of poolwide GDP for the best pool of countries that contains Chile, chosen among all 74 countries. We also show these lowest-standard-deviation envelopes for various restrictions on the universe of potential partners Chile can choose from. In particular, we display the cases when Chile can pool only with other emerging markets, developing countries, or advanced economies. To give a sense of the importance of choosing well one's risk sharing partners, we also plot the highest-standarddeviation envelope (that is, the least desirable pools from Chile's standpoint, for each pool size) among the 74 countries.

Several results deserve mention. First, the lowest possible standard deviation for poolwide GDP growth in a group that includes Chile (as it turns out, together with another 19 countries) is 0.61 percentage points, far below the 4.41 percentage points for Chile on its own. Second, a small number of carefully chosen partners is sufficient to yield the bulk of available risk sharing benefits. ${ }^{24}$ Even with just one well-chosen partner (in this case, France), poolwide standard deviation falls to 1.26 percentage points. The standard deviation of GDP growth reaches 0.72 percentage points, already quite close to the minimum, for the best pool of 7 members. ${ }^{25}$ Not surprisingly, this is a motley set of economies, including Austria, Cameroon, Chile, New Zealand, Nicaragua, Sweden, and Syria. In later sections, we discuss whether all potential partners would want to participate in this agreement from the strict standpoint of a reduction in volatility. For the time being, however, it is interesting to note that this is a Pareto improvement compared with the status quo: focusing exclusively on volatility reduction, each of the countries included is far better off in this pool than on its own. Indeed, the lowest-standard-deviation envelope shown in Figure 1 looks almost identical if one adds the constraint that pools should be Pareto improving, i.e., that volatility is lower for all participants under pooling than individually.

Third, marginal gains quickly become small. Based on the volatility criterion they become negative for groups above 20 members, and more visibly negative as the pool size increases further than, say, 30 members. Beyond a certain pool size, covariance benefits are no longer

\footnotetext{
${ }^{24}$ This result is reminiscent of the well-known finding in finance that a small set of stocks is often sufficient to provide most of the diversification opportunities available by holding the entire stock market (Solnik, 1974).

${ }^{25}$ The finding that most diversification gains can be attained in relatively small pools holds for all countries, including the United States, despite the large size of the U.S. economy. Pooling with another five or six wellchosen economies (including Japan, in the first instance) would imply a near halving of the volatility faced by U.S. residents.
} 


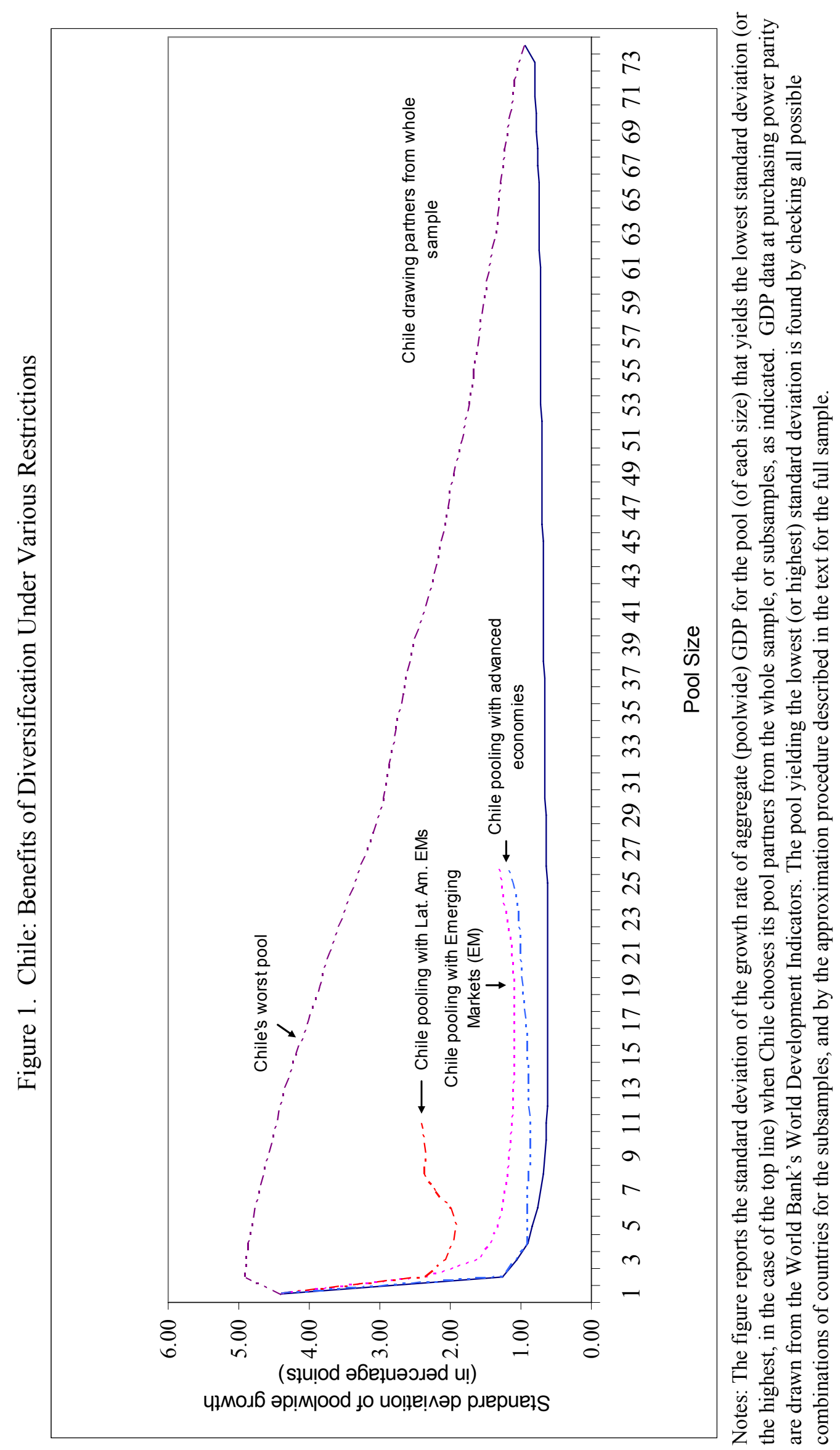


significant, and the pool starts having to include countries that have relatively high volatility. Note that these results go through exactly under the Obstfeld (1994) approach, in which welfare is a monotonic transformation of volatility. The same pools that provide the lowest volatility also yield the highest welfare. Marginal gains will no longer be negative, however, when allowing for the payment of entry transfers (i.e., for differences between $C_{0}{ }^{j}$ and $\underline{C}_{0}$ ). Under that setup, countries whose output properties would tend to increase the overall volatility of the pool could pay existing members in order to be allowed into the pool, and everybody would be better off.

Finally, the (upper) envelope corresponding to the worst possible pools of each size highlights the importance of choosing one's partners carefully: at small pool sizes, one runs the risk of achieving higher volatility in a poorly chosen pool than on one's own. Throughout this paper, we sometimes note, but typically do not focus on, the exact identities of the countries that form the best group. The reason is that poolwide volatility for the lowest-volatility group is only marginally below that for the groups with the second-lowest or third-lowest, and so on. Given that the differences are so small, it is likely that considerations outside our analysis would often lead countries not to choose the absolute best. ${ }^{26}$

Rather than exact country identities, we emphasize the extent to which various types of (economically relevant) constraints may reduce the maximum possible risk diversification benefits. For example, Figure 1 also reports the extent to which possible gains decline when the universe of countries that Chile can choose from is constrained by the level of economic and financial development, or geographically. The lowest possible standard deviation amounts to 0.61 percentage point when Chile is allowed to choose its pooling partners among all 74 countries, but 0.87 percentage point when it is constrained to pool with advanced countries only, 1.07 percentage point within the universe of emerging markets only, and 1.91 percentage points when pooling within Latin America only. Risk sharing agreements that are based on common geographic origins, or restricted to countries within a given range of per capita income, provide smaller gains than do pools formed by choosing from the unconstrained, worldwide sample.

\section{Variance Decomposition}

To illustrate the sources of risk diversification gains, it is useful to decompose the variance of the growth rate of poolwide income into a weighted average of the variances of individual countries' growth rates and a weighted sum of all bilateral covariances. In other words,

$$
\operatorname{Var}\left(g_{p}\right)=\operatorname{Var}\left(\sum_{i=1}^{p} w_{i} g_{i}\right)=\sum_{i}^{p} w_{i}^{2} \operatorname{Var}\left(g_{i}\right)+\sum_{i=1}^{p} \sum_{j=1}^{p} w_{i} w_{j} \operatorname{Cov}\left(g_{i}, g_{j}\right) \quad \text { for } i \neq j ; i=1, \ldots p
$$

\footnotetext{
${ }^{26}$ Suppose, for example, that Chile does not wish Costa Rica to join the pool because of the unfortunate outcome (1-2) of that soccer Copa America game in Tacna, Peru, in 2004. The best pool mentioned above, minus Costa Rica, implies a standard deviation of 0.65 percentage point, only 0.04 percentage point below the best, perhaps a small price to pay not to have to be reminded of that game.
} 
where $w_{i}$ denotes the share of country $i$ in the pool's production, $g_{p}$ is the growth of aggregate GDP for a pool of $p$ countries, and individual countries' growth rates are denoted by $g_{i}$. Countries are attractive partners to the extent that they have low variances and low (or, even better, negative) covariances with other members of the pool.

Table 1 performs this decomposition for the case of Chile. Not all of the countries involved have low variances; rather, low covariances are key here, which presumably reflects geographical distance and differences in economic structure. Moreover, countries (such as Syria in this example) that do not have an especially low covariance with respect to Chile may still be attractive partners as a result of relatively low (or negative) covariances with the other members of the pool.

Figure 2 plots the decomposition of poolwide variance for each pool size. ${ }^{27}$ Diversification gains for pool sizes up to about seven countries stem from both the addition of countries with lower volatility than Chile's and low (or negative) covariances. The first few countries have both low individual variances and negative covariances with Chile (as well as, importantly, with each other). However, the covariance gains diminish rapidly, as the sum of all bilateral covariances starts increasing again. From there on, the remaining diversification gains arise almost exclusively from the addition of countries with lower variance than Chile, but not with negative average covariances with the rest of the membership.

\section{Would all potential pool members agree to join?}

Two potential obstacles seem especially relevant to the ability to form the pools that the method used above would indicate as optimal for Chile. First, other potential participants may face more attractive alternatives - an issue that we begin to analyze in this section. Second, there may be concerns that the risk sharing contract would not be enforceable - an issue that we will address in later sections. For the time being, we continue to assume away the possibility of entry transfers.

As mentioned above, for each pool size, all countries involved are better off in the pool than on their own. ${ }^{28}$ But for each country to agree to participate in the risk sharing scheme, Pareto improvement is only a necessary condition: the proposed pool must be the best one possible from the standpoint of each potential member; indeed, we will define as "stable" those pools that have this property.

\footnotetext{
${ }^{27}$ The decomposition is performed using fixed weights, given by the initial values of GDP shares. This introduces a small discrepancy compared with the identity reported in the text, because countries' relative weights change over time as their economic growth rates differ. The discrepancies are similar using average shares.

${ }^{28}$ The only exception is the envelope for the Latin American sample, where the Pareto-improving standard deviations are often somewhat above those reported in Figure 1.
} 
Table 1. Components Accounting for the Variance of the Best Pool of Seven Countries for Chile

\begin{tabular}{|c|c|c|c|c|c|}
\hline \multicolumn{6}{|c|}{ i. Individual country variances } \\
\hline Country & $w_{i}$ & $\sigma_{i} * 100$ & $\left(w_{i}^{2} \sigma_{i}^{2}\right) * 1000$ & & \\
\hline Austria & 0.310 & 1.659 & 0.027 & & \\
\hline Sweden & 0.354 & 1.442 & 0.026 & & \\
\hline Chile & 0.094 & 4.405 & 0.017 & & \\
\hline Nicaragua & 0.043 & 8.975 & 0.015 & & \\
\hline New Zealand & 0.119 & 2.642 & 0.010 & & \\
\hline Syria & 0.046 & 5.190 & 0.006 & & \\
\hline Cameroon & 0.035 & 6.800 & 0.005 & & \\
\hline Sum (i) & & & 0.106 & & \\
\hline \multicolumn{6}{|c|}{ ii. Covariances with Chile } \\
\hline Country $i$ & Country $j$ & $w_{i}$ & $w_{j}$ & $\sigma_{i j} * 1000$ & $\left(w_{i} w_{j} \sigma_{i j}\right) * 1000$ \\
\hline Chile & Cameroon & 0.094 & 0.035 & -0.375 & -0.002 \\
\hline Chile & New Zealand & 0.094 & 0.119 & -0.230 & -0.005 \\
\hline Chile & Nicaragua & 0.094 & 0.043 & -0.194 & -0.002 \\
\hline Chile & Austria & 0.094 & 0.310 & -0.157 & -0.009 \\
\hline Chile & Sweden & 0.094 & 0.354 & -0.007 & -0.001 \\
\hline Chile & Syria & 0.094 & 0.046 & 0.591 & 0.005 \\
\hline
\end{tabular}

iii. Other covariances

\begin{tabular}{|c|c|c|c|c|c|}
\hline Country $i$ & Country $j$ & $w_{i}$ & $w_{j}$ & $\sigma_{i j} * 1000$ & $\left(w_{i} w_{j} \sigma_{i j}\right) * 1000$ \\
\hline Austria & New Zealand & 0.310 & 0.119 & -0.204 & -0.015 \\
\hline Nicaragua & Sweden & 0.043 & 0.354 & -0.380 & -0.012 \\
\hline Sweden & Syria & 0.354 & 0.046 & -0.213 & -0.007 \\
\hline Cameroon & Sweden & 0.035 & 0.354 & -0.213 & -0.005 \\
\hline Austria & Nicaragua & 0.310 & 0.043 & -0.178 & -0.005 \\
\hline New Zealand & Syria & 0.119 & 0.046 & -0.361 & -0.004 \\
\hline Cameroon & Syria & 0.035 & 0.046 & -1.176 & -0.004 \\
\hline Austria & Syria & 0.310 & 0.046 & -0.123 & -0.004 \\
\hline Cameroon & New Zealand & 0.035 & 0.119 & -0.378 & -0.003 \\
\hline Nicaragua & Syria & 0.043 & 0.046 & 0.293 & 0.001 \\
\hline Cameroon & Nicaragua & 0.035 & 0.043 & 0.712 & 0.002 \\
\hline New Zealand & Nicaragua & 0.119 & 0.043 & 0.243 & 0.003 \\
\hline Austria & Cameroon & 0.310 & 0.035 & 0.132 & 0.003 \\
\hline Austria & Sweden & 0.310 & 0.354 & 0.014 & 0.003 \\
\hline New Zealand & Sweden & 0.119 & 0.354 & 0.068 & 0.006 \\
\hline Sum (iii) & & & & & -0.040 \\
\hline (i) $+($ ii $)+($ iii $) * 1000$ & 0.052 & \multicolumn{2}{|c|}{ True variance of best pool*1000 } & 0.052 & \\
\hline
\end{tabular}

Notes: The variance of the growth rate of aggregate GDP for the best pool of seven countries (including Chile) is split into (i) the sum of the variances of individual country growth rates, (ii) the sum of the covariances with Chile, and (iii) the sum of the covariances among the other countries in the pool. As growth rates differ across countries, and the weights $w_{i}$ used are set constant at the 1975 levels, there is a small discrepancy. GDP data are from the World Bank's World Development Indicators. 
Figure 2. Components Accounting for Chile's Variance in the Best Pools of Each Size

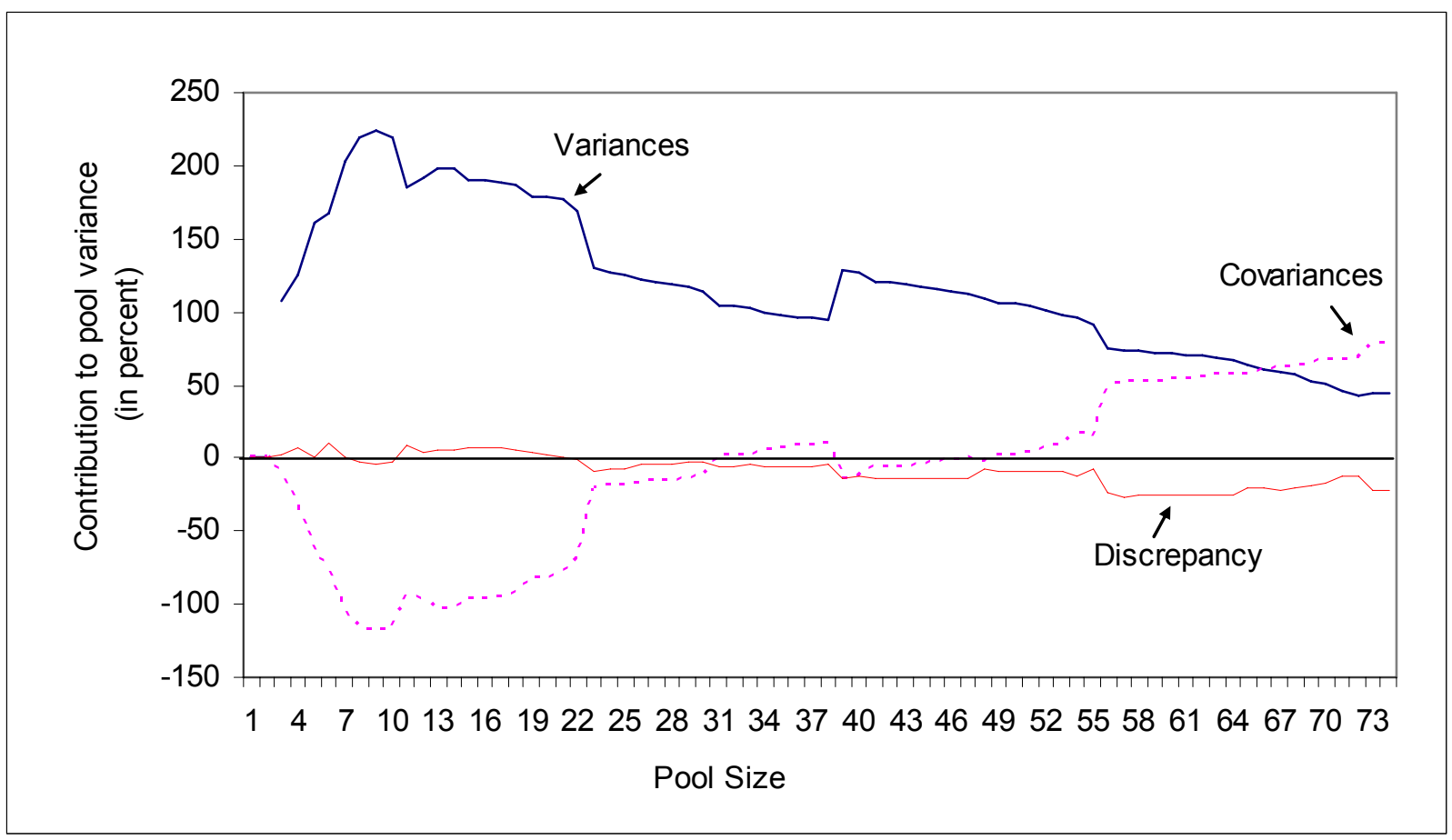

(Percent of Total Variance)

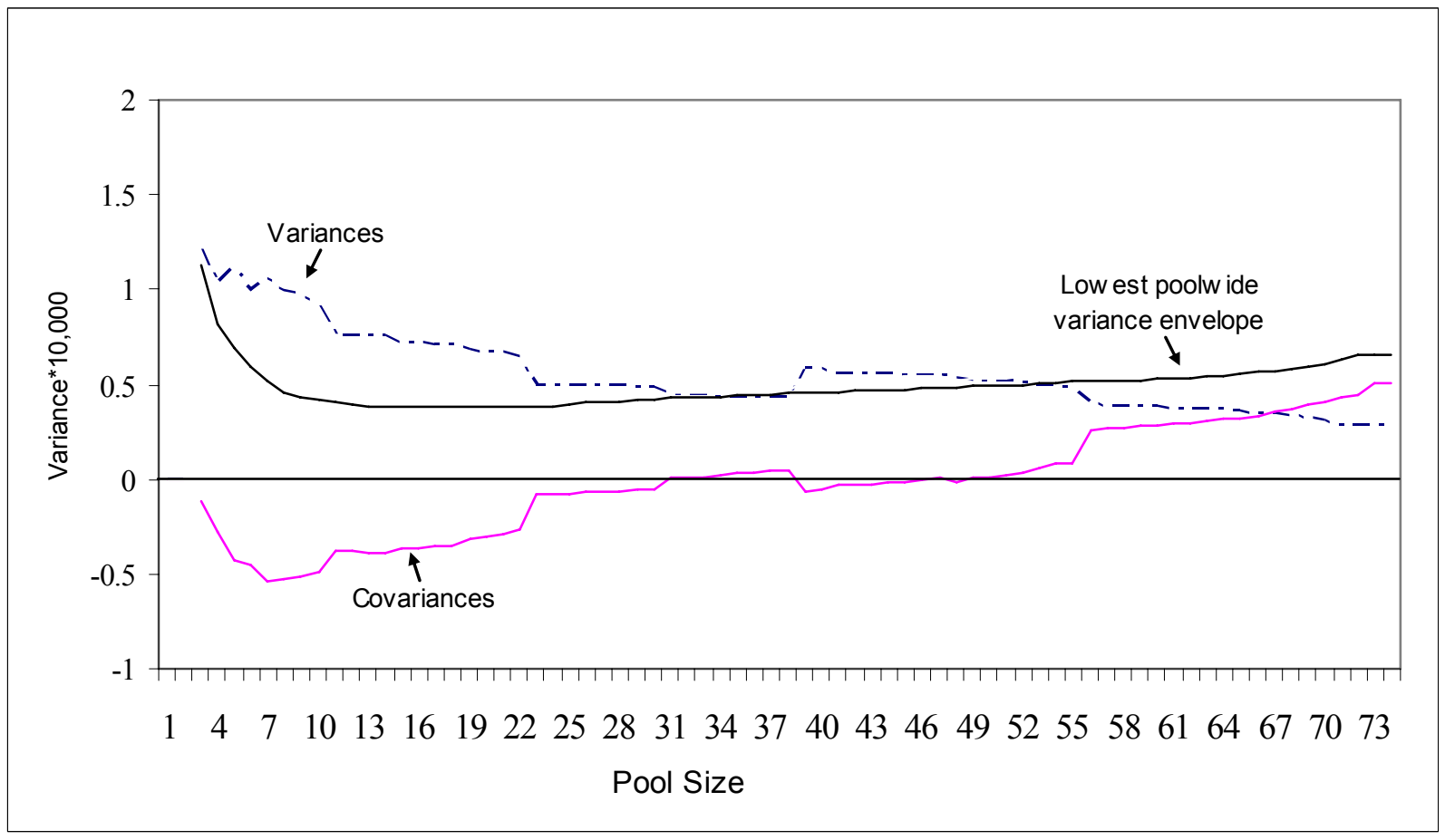

Notes: For the best pool of each size, poolwide variance is split into two components: the weighted sum of the variances of the individual pool members' growth rates and the weighted sum of bilateral covariances between all pairs of pool members. Thus, summing the terms "variances" and "covariances" vertically, one obtains the lowest poolwide variance envelope, except for a small discrepancy (Figure 2b) due to changes in weights as pool member countries' growth rates differ. The weighted sums of variances and covariances depicted in the figures are computed holding weights constant at their 1975 levels. GDP data are from the World Bank's World Development Indicators. 
We focus once again on the Chilean case, where the lowest standard deviation of poolwide growth is obtained for a group of 20 member countries, listed in Figure 3. In this example, on the basis of volatility reduction, not a single one of the nineteen countries party to Chile's optimal grouping would participate in the agreement. They all have more attractive alternatives available. Figure 3 plots the minimum standard deviation envelope for the countries that form the pool with minimal variance from Chile's standpoint. All potential participants would prefer alternative agreements that would provide them with even lower volatilities, typically by around 0.1 percentage point.

We illustrate the implications of requiring that a pool of a given size be the best possible for all participants. Table 2 reports the standard deviation of poolwide growth for the thus-defined stable pools that include Chile as a member, for each size up to seven only, owing to computational constraints. The stable pools usually provide lower diversification benefits than the pools identified without imposing the constraint that the pool be the best possible pool for all members. Thus, on the whole, considerations related to the "stability" of pools suggest that potential gains remain large but are somewhat lower if one takes into account that arrangements need to deliver minimal volatility (or at least not far from the minimum) for all participants.

The example presented in this section suggests several results that will be confirmed and fleshed out through more systematic analysis in the next sub-section. On the basis of risk diversification alone, there is little need for arrangements including many countries, as long as one's partners are chosen carefully. Welfare gains can in principle be sizeable even in small pools formed on a regional basis or where membership is constrained to countries with relatively low economic development. However, pools that deliver the greatest diversification benefits seem to consist of heterogeneous countries with respect to geography, as well as economic and financial development. In Section IV, we will provide a more systematic analysis of the impact of imposing constraints on the sample of potential partner countries. In the next subsection, we confirm the findings obtained above, but in a more general exercise that no longer restricts optimal pools to include any given country.

\section{Global Diversification}

Figure 4 reports the envelope of minimal volatility for all pool sizes $p$ in $[1,74]$, where we no longer require that a given economy be part of all the groups. As in the previous section, the bulk of possible diversification gains is attained with relatively small pools. ${ }^{29}$ The global best using the pure volatility criterion is a pool of 17 countries, which delivers a standard deviation

\footnotetext{
${ }^{29}$ As in Figure 2, we decomposed the poolwide variance of the optimal pool of each given size into the contributions of the sum of individual countries' variances and the sum of the covariances. For small pool sizes, we found that low (and usually negative) bilateral covariances account for more than half of the overall volatility reduction. The covariance term was more important than in Figure 2, because it is easier to find negative correlations in unconstrained pools of countries than in the case where one of the countries is always included by assumption. These results are omitted for the sake of brevity.
} 


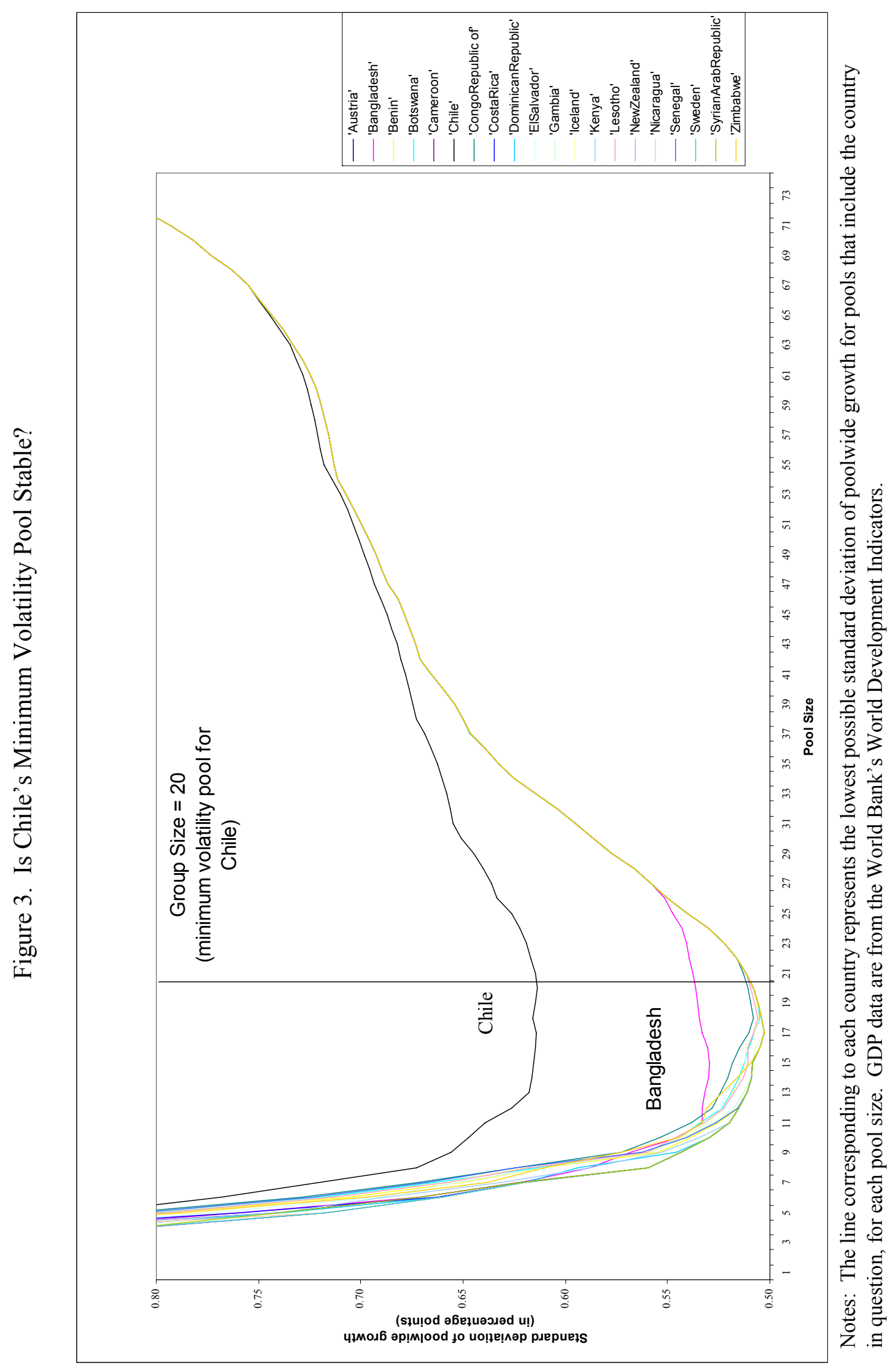




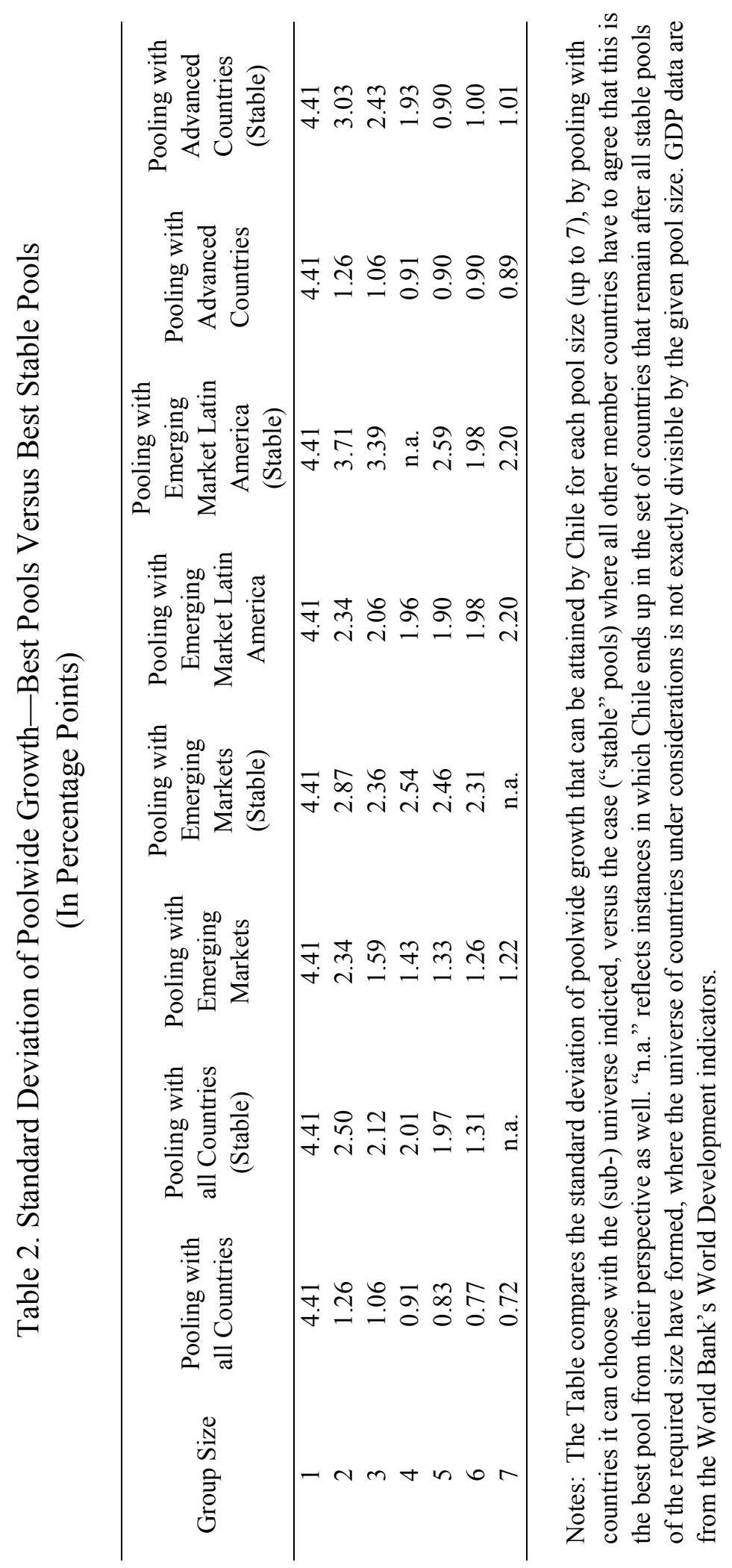




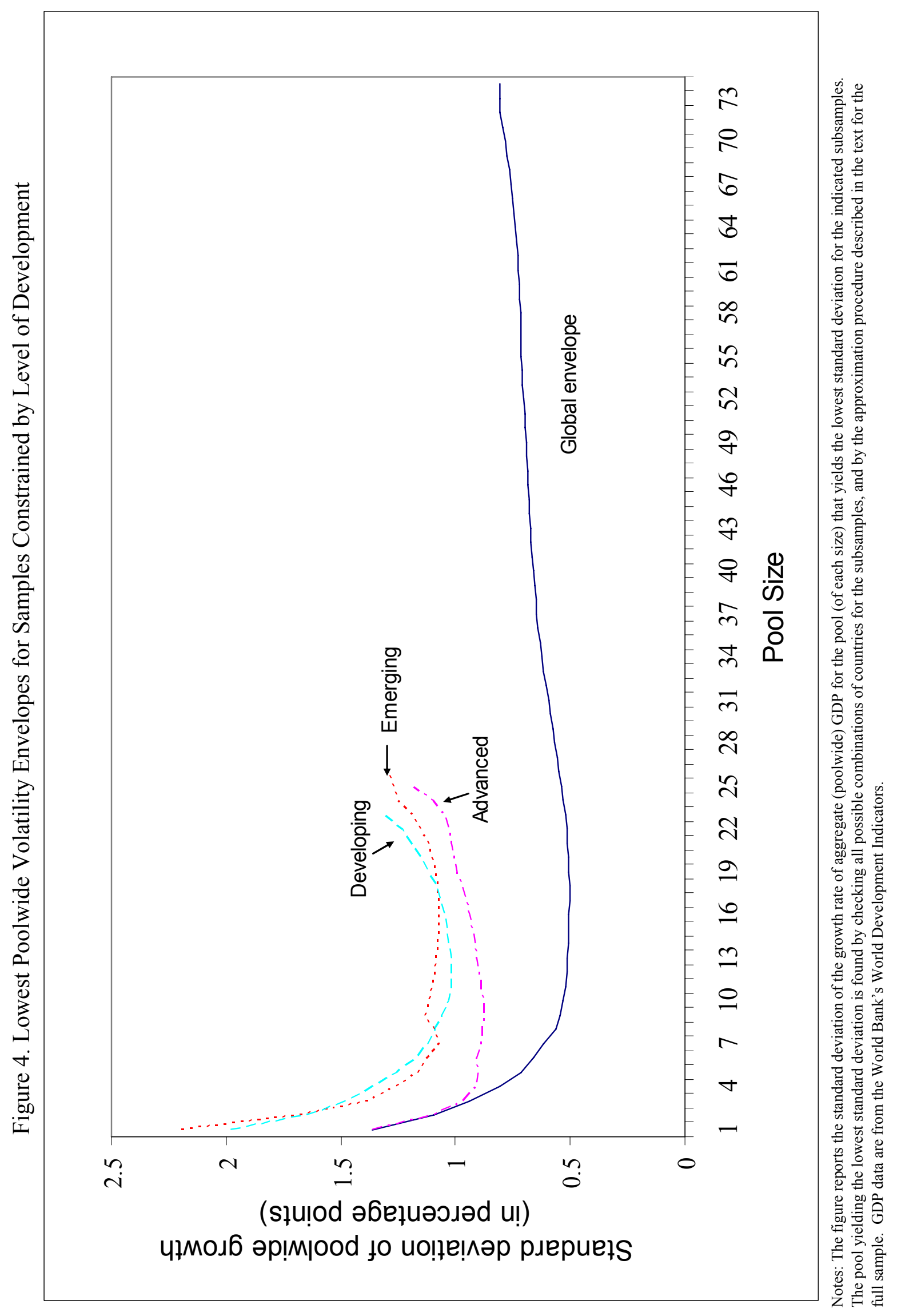


equal to 0.50 percentage points. ${ }^{30}$ However, the standard deviation is already as low as 0.62 percentage points for the best pool of size $7 .{ }^{31}$ The property that diversification gains are achieved within groups consisting of a small number of countries continues to prevail in this general setup.

The value reported for $p=1$ corresponds to the standard deviation of the individual growth rate for the least volatile country during the sample period, namely France. Diversification gains for specific countries cannot be easily read off the figure, because the identities of countries involved in the various optimal pools of different sizes may well change. But we know the identities of the relevant groupings, and can thus assess the gains that optimal pooling would provide to member countries. For example, in the case of the optimal group of size 7 mentioned above, the standard deviations of individual countries' growth rates range from 1.44 percentage points for Sweden to 8.97 percentage points for Nicaragua. The diversification gains are thus distributed unequally, with far larger gains accruing to countries with more volatile individual growth rates. This asymmetry would have implications for "entry transfers."

The list of countries involved in optimal pools confirms that heterogeneity is key. Interestingly, the list overlaps quite substantially with that obtained for the case of Chile. Several of the same countries come up as members of the best pools of smaller sizes (where we run a search over all possible pools, without any approximation) and continue to be present throughout all optimal pools for $p>7$. Again, we do not think that this is an artifact of our approximation method, despite the recursive structure it imposes onto the search, because the procedure leaves plenty of opportunities for countries to drop out of the best pool as size increases. Rather, the evidence suggests that the sample of countries providing the best mutual hedging properties within a universe of 74 economies is relatively small and robust. For example, the country with lowest individual volatility, France, does not enter any of the "best" groupings, likely because its growth cycle is highly correlated with many other economies in the sample. This reinforces the empirical relevance of low (or negative) covariances.

From a pure volatility standpoint, the groups that trace the envelope charted in Figure 4 are by definition both Pareto-improving and stable for a given pool size. And the best pool of 17 countries that attains the lowest standard deviation of aggregate poolwide growth is stable regardless of pool size considerations: none of the countries that form this globally best pool would have an incentive to deviate to alternative pools of any size on the basis of volatility reduction, if entry transfers are ruled out. Related exercises are conducted in somewhat greater detail in the Appendix.

\footnotetext{
${ }^{30}$ Austria, Bangladesh, Benin, Botswana, Cameroon, Chile, Rep. Congo, Costa Rica, Dominican Republic, El Salvador, Gambia, Iceland, Kenya, Lesotho, New Zealand, Nicaragua, Senegal, Sweden, Syrian Arab Republic, and Zimbabwe.

${ }^{31}$ Austria, Colombia, Costa Rica, Dominican Republic, New Zealand, Nicaragua, and Sweden.
} 
Figure 4 also reports the minimum standard deviation of the poolwide growth rate for samples constrained to the advanced countries, emerging markets, and developing countries, respectively. While risk diversification gains are substantial within each subsample, they are not as large as in the full universe of countries. The envelopes for emerging and developing economies are roughly one percentage point above the global envelope, for all $p$. For $p<3$, the global envelope and that corresponding to advanced economies coincide, but for larger pool sizes even advanced countries are considerably better off in pools that allow them to share risk with emerging market and developing countries. On the whole, advanced economies achieve somewhat smaller gains. This is consistent with the well known observation that advanced economies experience little volatility compared with other countries, and have correlated business cycles. The rapid exhaustion of diversification opportunities continues to hold in all three sub-samples.

\section{Welfare Gains}

We now turn to welfare, and allow for the payment of entry transfers. We still constrain the expected growth rate to be the same for all countries - an assumption we relax later. Figure 5 reports the total (income-weighted) welfare gains $\sum_{j=1}^{N} \delta^{j} Y_{0}^{j}$ for the best pool of each size, normalized by total income for the whole (sub-)universe of countries. The total gains are monotonically increasing with pool size, and attain a maximum when the entire (sub)universe of countries under consideration are pooling together. Just as volatility decreased rapidly in the number of member countries, so do most of the welfare gains materialize in small-sized groupings, with marginal welfare gains petering out for pools beyond seven or eight members. Again, the rapid decline in marginal welfare gains holds when the exercise is conducted for subsamples of countries consisting of advanced, emerging, and developing countries only, respectively. For the case where the pool eventually consists of the entire 74-country sample for which we have data, total gains amount to 1.9 percent of initial worldwide income (Table 3). Even allowing for entry transfers, the gains are far larger for those groups of countries that start out with higher volatility prior to pooling: expressed as a share of initial income for the group under consideration, total (income-weighted) welfare gains amount to 0.7 percent for the advanced countries, 4.4 percent for the emerging markets, and 7.4 percent for the developing countries. From the perspective of individual countries, the size of the gains differs considerably, depending on the country's individual volatility under the status quo. In the full sample, the minimum (United States) annual gains amount to 0.5 percent of initial country income, and the median gain (Dominican Republic) is 4.1 percent. 


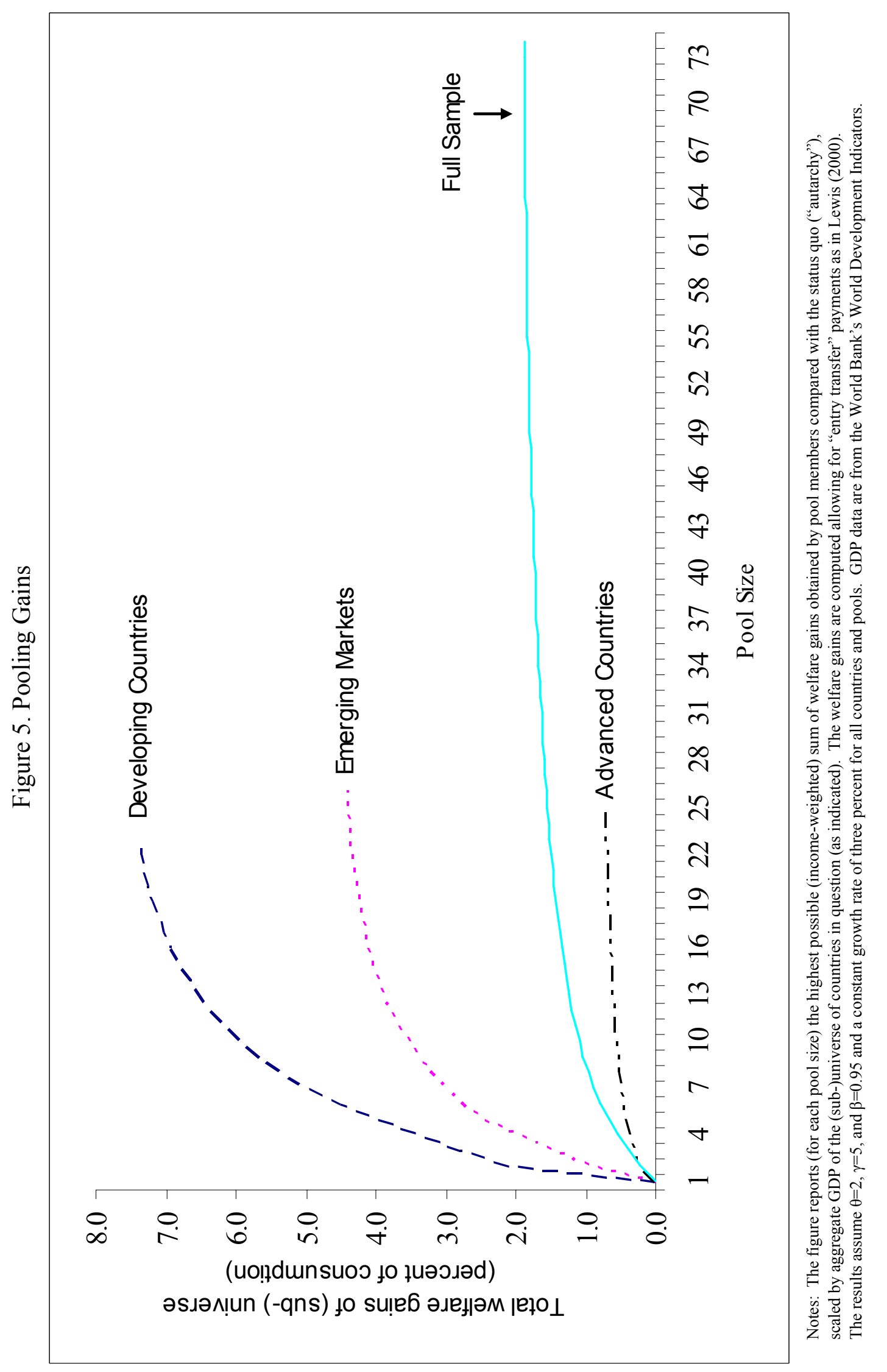


Table 3. Welfare Gains Allowing for "Entry Transfers"

(percent of initial income)

\begin{tabular}{|c|c|c|c|}
\hline & Minimum Gain & Median Gain & $\begin{array}{l}\text { Gains as a Share of } \\
\text { Initial GDP for } \\
\text { Sub-Sample Indicated }\end{array}$ \\
\hline Full Sample & $\begin{array}{c}0.55 \\
\text { United States }\end{array}$ & $\begin{array}{c}4.10 \\
\text { Dominican Republic }\end{array}$ & 1.87 \\
\hline Advanced Countries & $\begin{array}{c}0.40 \\
\text { United States }\end{array}$ & $\begin{array}{c}0.89 \\
\text { Australia }\end{array}$ & 0.69 \\
\hline Emerging Markets & $\begin{array}{c}1.67 \\
\text { Colombia }\end{array}$ & $\begin{array}{c}4.97 \\
\text { Malaysia }\end{array}$ & 4.39 \\
\hline Developing Countries & $\begin{array}{c}1.00 \\
\text { Bangladesh }\end{array}$ & $\begin{array}{c}7.17 \\
\text { Madagascar }\end{array}$ & 7.37 \\
\hline
\end{tabular}

Notes: Minimum, median, and total welfare gains for subsamples indicated. Computed allowing for the possibility of "entry transfers" but assuming the same expected growth ( 3 percent) across countries. The results assume $\theta=2$, $\gamma=5$, and $\beta=0.95$. The list of subsamples is provided in Appendix Table 1. GDP data are from the World Bank's World Development Indicators.

\section{Choosing Partners within Subsamples}

In this section we quantify the foregone diversification and welfare gains implied by the need to choose one's pooling partners within specific sub-samples. In particular, we seek to assess the importance of choosing partner countries where contract enforcement and monitoring may be easy. We approximate the concept in a variety of ways, splitting our sample according to: (i) the level of development and country size; (ii) institutional quality and past payment record on international debt obligations; (iii) the degree of international financial integration; (iv) geographical region; and (v) bilateral trade intensity. In all these cases, we present the results based on simple volatility criteria, as well as welfare computed with and without entry transfers. We report the main results in Table 4, for the best possible pool of any size. Appendix Tables 2 and 3 provide the same results for a variety of pool sizes. They confirm that the patterns of rapid declines in volatility and marginal welfare gains hold within each sub-sample considered in this section. Finally, we consider existing risk-sharing arrangements such as the Chiang-Mai Initiative or FLAR, or other types of existing arrangements whereby participants have long established cooperation-for example, in the context of a currency union or a trade agreement. We estimate the extent to which participant countries would be able to obtain larger welfare gains in pools of the same size if they were to choose their partners in an unconstrained manner. 
Table 4. Gains from Risk Pooling Among Countries

\begin{tabular}{|c|c|c|c|c|}
\hline & (1) & (2) & (3) & (4) \\
\hline & $\begin{array}{c}\sigma \text { Individual } \\
\text { Country } \\
\text { Alone }\end{array}$ & $\begin{array}{c}\sigma \text { Best } \\
\text { Pool of } \\
\text { Any Size }\end{array}$ & $\begin{array}{c}\delta \text { Best } \\
\text { Pool of } \\
\text { Any Size }\end{array}$ & $\begin{array}{c}\text { Total } \\
\text { Income- } \\
\text { Weighted } \\
\text { Sum of } \\
\text { Gains }\end{array}$ \\
\hline All Countries (Pooling with any country) & 3.62 & 0.54 & 3.88 & 1.87 \\
\hline \multicolumn{5}{|l|}{ Interest in Risksharing, by Level of Development, Size } \\
\hline Advanced (pooling with any country) & 2.01 & 0.62 & 1.05 & 0.79 \\
\hline Advanced (pooling only with advanced) & 2.01 & 0.89 & 0.86 & 0.69 \\
\hline Emerging (pooling with any country) & 4.01 & 0.61 & 5.22 & 4.61 \\
\hline Emerging (pooling only with emerging) & 4.01 & 1.07 & 4.65 & 4.39 \\
\hline Developing (pooling with any country) & 5.15 & 0.51 & 9.14 & 8.04 \\
\hline Developing (pooling with only developing) & 5.15 & 1.01 & 8.16 & 7.37 \\
\hline Small Countries (pooling with any country) & 4.50 & 0.51 & 6.29 & 5.81 \\
\hline Small Countries (pooling only with small countries) & 4.50 & 0.87 & 6.13 & 5.56 \\
\hline \multicolumn{5}{|l|}{ Current Degree of International Financial Integration } \\
\hline High Integration Countries (pooling with any country) & 2.61 & 0.61 & 1.94 & 1.32 \\
\hline High Integration Countries (pooling only with high integration countries) & 2.61 & 0.74 & 1.84 & 1.30 \\
\hline Low Integration Countries (pooling with any country) & 4.36 & 0.51 & 5.83 & 4.58 \\
\hline Low Integration Countries (pooling only with low integration countries) & 4.36 & 0.76 & 5.55 & 4.21 \\
\hline \multicolumn{5}{|l|}{ Costs of Weak Enforcement } \\
\hline Excellent Enforceability Countries (pooling with any country) & 2.11 & 0.61 & 1.17 & 0.85 \\
\hline Below Excellent Enforceability Countries (pooling with any country) & 4.41 & 0.52 & 5.90 & 5.12 \\
\hline $\begin{array}{l}\text { Excellent Enforceability Countries (pooling only with excellent } \\
\text { enforceability countries) }\end{array}$ & 2.11 & 0.87 & 1.03 & 0.76 \\
\hline $\begin{array}{l}\text { Emerging and Developing Country Excellent Enforceability (pooling with } \\
\text { any excellent enforceability) }\end{array}$ & 4.08 & 0.87 & 4.94 & 2.98 \\
\hline $\begin{array}{l}\text { Emerging and Developing Excellent Enforceability (pooling only with } \\
\text { emerging and developing excellent enforceability) }\end{array}$ & 4.08 & 2.25 & n.a. & 1.52 \\
\hline Above Average Institutional Quality (pooling with any country) & 2.61 & 0.61 & 1.94 & 1.06 \\
\hline Below Average Institutional Quality (pooling with any country) & 4.26 & 0.52 & 5.32 & 5.42 \\
\hline $\begin{array}{l}\text { Above Average Institutional Countries (pooling with only above average } \\
\text { institutional countries) }\end{array}$ & 2.61 & 0.82 & 1.74 & 0.99 \\
\hline $\begin{array}{l}\text { Above Average Institutional Emerging and Developing Country (pooling } \\
\text { with any above institutional country) }\end{array}$ & 4.38 & 0.59 & 5.53 & 3.59 \\
\hline $\begin{array}{l}\text { Above Average Institutional Emerging and Developing (pooling only with } \\
\text { above average institutional emerging and developing) }\end{array}$ & 4.38 & 1.64 & 5.08 & 2.83 \\
\hline \multicolumn{5}{|l|}{ Costs of Regional Constraints } \\
\hline European Union (pooling only with advanced) & 1.84 & 0.89 & 0.75 & 0.77 \\
\hline European Union (pooling only with EU) & 1.84 & 1.05 & 0.68 & 0.55 \\
\hline Asian Emerging (pooling only with emerging) & 3.62 & 1.09 & 3.60 & 3.54 \\
\hline Asian Emerging (pooling only with Asian emerging) & 3.62 & 1.84 & 2.98 & 2.94 \\
\hline Latin American Emerging (pooling only with emerging) & 4.41 & 1.07 & 5.73 & 5.39 \\
\hline Latin American Emerging (pooling only with Latin American emerging) & 4.41 & 1.90 & 4.96 & 4.08 \\
\hline
\end{tabular}

Notes: Column (1) reports the median (across countries in the indicated sub-sample) standard deviation of individual country growth. Column (2) reports the median (across countries in the indicated sub-sample) of the lowest possible standard deviation of poolwide growth. Column (3) reports the median welfare gain (across countries in the indicated sub-sample) obtained by entering the best possible pool of any size chosen within the indicated sub-sample without the possibility of entry transfers, and with pool and individual country growth assumed to be fixed at 3 percent per annum. Column (4) reports the income-weighted sum of welfare gains generated by a pool of all countries in the sub-sample, expressed as a share of total initial income for the indicated sub-sample with the possibility of entry transfers, and with pool and individual country growth assumed to be fixed at three percent per annum. 


\section{A. Level of Development and Country Size}

The degree of volatility reduction and welfare gains that can be attained by pooling countries within categories defined on the basis of the level of economic development is informative in two respects. First, it helps gauge the potential interest in pooling risk on the part of countries belonging to different income groups. Second, one might argue that countries are more likely to feel comfortable pooling with others of a similar income group (or at least as high an income group).

In Table 4, for each sub-sample we report the median value of the standard deviation of individual countries' growth rates across the countries within the sub-universe (first column). Then, for each country we search over all possible pools of any size that it can form together with others chosen within the sub-sample. We note the lowest achievable standard deviation of poolwide growth, and report the median value of that standard deviation across all countries in the sub-sample (second column). We then compute for each country the welfare gain obtained by joining its best pool, assuming that all countries have the same expected growth rate and that there are no entry transfers, following Obstfeld (1994). ${ }^{32}$ We report the median value of these gains across countries in the sub-universe (third column). Finally, we allow entry transfers and report the sum of the income-weighted welfare gains that would obtain if all countries in the sub-universe were to join together to form a pool (fourth column).

For the typical advanced country, the standard deviation of the growth rate can be cut from 2.0 percentage points under autarchy to 0.6 percentage points when moving into the lowestvolatility pool drawn for the entire universe of countries, and 0.9 percentage points when pooling with other advanced countries only. The corresponding welfare gains can be as high as 1.1 percentage point of annual consumption when pooling within the universe of all countries, and 0.8 percentage point when pooling among advanced countries only. Allowing for entry transfers, the total welfare gains to the advanced countries (as a share of initial income of all advanced countries) are 0.8 percent when all countries in the universe for which we have data are pooling together, and 0.7 percent when all advanced countries are pooling together. The gains are much larger for emerging markets. The total gains as a share of initial income are 4.4 percent when - allowing for entry transfers - all emerging markets pool together, and even greater for developing countries (7.4 percent).

\section{Country Size}

Interest in the risksharing gains provided by pooling is likely to be higher for small countries, which — on average — are prone to greater volatility. The estimates confirm that small countries

\footnotetext{
${ }^{32}$ The results correspond to $\gamma=5, \theta=2$, and $\beta=0.95$. Results for alternative parameter values are available from the authors upon request.
} 
(defined as those with a population below 5.2 million in 1970) would attain substantial volatility reduction through pooling, and the ensuing welfare benefits would be similarly large.

Interestingly, small countries pooling among themselves attain almost as high risksharing gains as they would if they were to pool within the whole universe of countries in our sample.

\section{B. Institutional Quality and Past Payment Record}

We explore the effects of restricting the sample on the basis of whether countries have defaulted in the recent past or whether they receive high scores on measures of institutional quality and are thus perceived as likely to comply with contracts. We consider two definitions. The first, labeled "excellent enforceability" includes all countries that were in the top half of the distribution of the institutional quality index compiled by Kaufmann and others (2005), and that never experienced severe international repayment difficulties during 1970-2004. ${ }^{33}$ The second, "above-average institutional quality" is based on the institutional quality index only. ${ }^{34}$ The median country with excellent enforceability experiences volatility of 2.1 percentage points. When pooling with other excellent enforceability countries only, volatility can decline to 0.9 percentage points, and further down to 0.6 percentage points when pooling in an unconstrained universe. Similarly, the median country with above-average institutional quality has volatility of 2.6 percentage points, which falls to 0.8 percentage point in the best pool within the same sample, but even further, to 0.6 percentage point, when pooling within the whole sample. Available income-weighted welfare gains are equivalent to 0.8 percentage points of annual consumption within the universe of countries with a reputation for "excellent enforceability", and 1.0 percentage points within the universe of countries with above-average institutional quality. In contrast, the gains would be much larger for "below-excellent enforceability" countries (5.12 percentage points of annual consumption) or "below-average institutional quality" countries (5.42 percentage points). The general message here is that potential risk sharing gains are smaller within subsamples consisting of countries with better perceived enforceability.

On a more optimistic note, however, consider the risk sharing opportunities available to those few emerging market and developing countries that are perceived to have excellent enforceability (Botswana, Hungary, Malaysia, and South Africa). Their median volatility declines from 4.1 percentage points of GDP to 2.2 percentage points if they can pool together, and to 0.9 percentage points if they draw their pooling partners from the excellent enforceability countries. ${ }^{35}$ Welfare gains for these countries when they pool with the rest of the world are

\footnotetext{
${ }^{33}$ Default history is drawn from Reinhart, Rogoff and Savastano (2003) and Detragiache and Spilimbergo (2001).

${ }^{34}$ In addition to the advanced countries, "excellent enforceability" includes four emerging market and developing countries, whereas "above-average institutional quality" includes eight emerging markets and three developing countries.

${ }^{35}$ A similar result holds using the concept of "above-average institutional quality" instead.
} 
3 percent of initial income. Thus, if insufficient enforceability/institutional quality is indeed what prevents emerging and developing countries from entering into pooling arrangements, then there would seem to be a strong incentive for such countries to improve in this dimension.

\section{International Financial Integration}

To some extent, many countries are already integrated in global financial markets, though it is well known that such integration is still far from resulting in complete risk sharing. Current cross-country differences in the degree of international financial integration may be a proxy for the ability to be credible participants in pooling arrangements such as those considered in this paper. It may be interesting to quantify potential welfare gains, using this measure of the likelihood that countries would be able to abide by the obligations of pooling arrangements.

We divide the sample into high integration and low integration countries based on whether they are in the top or bottom half of the sample when ranked by total foreign assets to GDP, using the Lane and Milesi-Ferretti (2006) data set. As might be expected, we find that the countries whose international financial integration is already relatively high have lower interest in further international risksharing. The total income-weighted sum of welfare gains (as a share of the group's initial income) is 4.2 percent for low-integration countries, and 1.3 percent for highintegration countries.

\section{Regional Constraints}

In practice, existing or prospective pools are often formed on a regional basis. We analyze the implications of geographical constraints through a few examples. We estimate the gains that the advanced European countries would obtain if they were only allowed to pool with other advanced European countries, and compare them to the gains that would obtain if they were allowed to pool with all other advanced countries without geographic restrictions. Similarly, we compare the gains available to Asian emerging or, separately, Latin American emerging market pools, with the gains obtained within the sample of all emerging markets.

Geographical constraints do not turn out to be very important for advanced European countries, presumably because they constitute a high proportion of advanced countries, and because the advanced country cycle has a large worldwide common component. The median advanced European country can cut its volatility from 1.8 percentage points to 1.0 percentage point in a pool of advanced European countries, and to a rather similar 0.9 percentage point in a pool of advanced countries chosen worldwide. The same message holds using welfare gains.

In contrast, geographical constraints seem more relevant for the emerging markets' ability to reduce volatility. For instance, median volatility for Latin American emerging markets equals 4.4 percentage points and can be lowered to 1.9 percentage point by pooling with five well chosen Latin American emerging markets, but to as low as 1.3 (1.1) percentage point by pooling 
with five (ten) emerging markets in the absence of geographical constraints. Similarly, the median Asian emerging market can reduce its volatility from 3.6 percentage points to 1.8 percentage points in a pool of seven Asian emerging markets, and to 1.1 percentage points in a pool of ten emerging markets chosen also from outside the region. The impact of geographical constraints remains substantial, although it becomes smaller, when measured in terms of welfare. For Latin American emerging markets, welfare gains can amount to 5.4 percentage points of initial income when pooling within the whole universe of emerging markets, but also gains of 4.1 percentage points when pooling within emerging Latin America. Asian emerging markets can obtain welfare gains equivalent to 3.6 percentage points of initial income when pooling within the whole universe of emerging markets, but also gains of up to 3.0 percentage points when pooling within emerging Asia. ${ }^{36}$

\section{E. Trade Integration}

In this sub-section, we explore further the theme of contract enforceability, which we relate to trade patterns and the associated regional element often observed in actual pooling arrangements. Trade linkages imply, on the one hand, higher output correlations and thus reduced diversification possibilities but, on the other hand, greater ability to enforce risk sharing contracts, because defaulting partners can be sanctioned via exclusion from goods trade (see, for example, Rose and Spiegel, 2004). This may explain the regional element observed in actual pooling arrangements, suggesting that the impact on contract enforceablility may in some cases prevail over the impact on diversification opportunities. While other factors (such as political or cultural links) may also underlie the desire to form regional agreements, direction of trade data are easily available and lend themselves naturally to quantitative analysis in the context of our approach.

To measure trade integration within a pool, we sum exports across all pool members as a ratio to poolwide GDP. We then consider all possible pools and analyze the correlation between this measure of trade integration with the minimal volatility of poolwide output. As is well known, trade is substantially lower among emerging markets than it is among advanced countries, and it is even lower among developing countries. We analyze separately the relationship between trade integration and poolwide output volatility for all possible pools of (i) advanced economies, (ii) emerging markets, and (iii) developing countries. The relationship is depicted in Figure 6 for pool sizes 5 and 10. The results suggest that greater trade integration is clearly associated with a larger minimal poolwide volatility within the universe of emerging markets and, separately, developing countries. The relationship is weaker among advanced economies, where risk sharing gains are smaller to begin with.

\footnotetext{
${ }^{36}$ This reflects the strong non-linearity of welfare as a function of volatility.
} 
Figure 6. Trade and Diversification Benefits
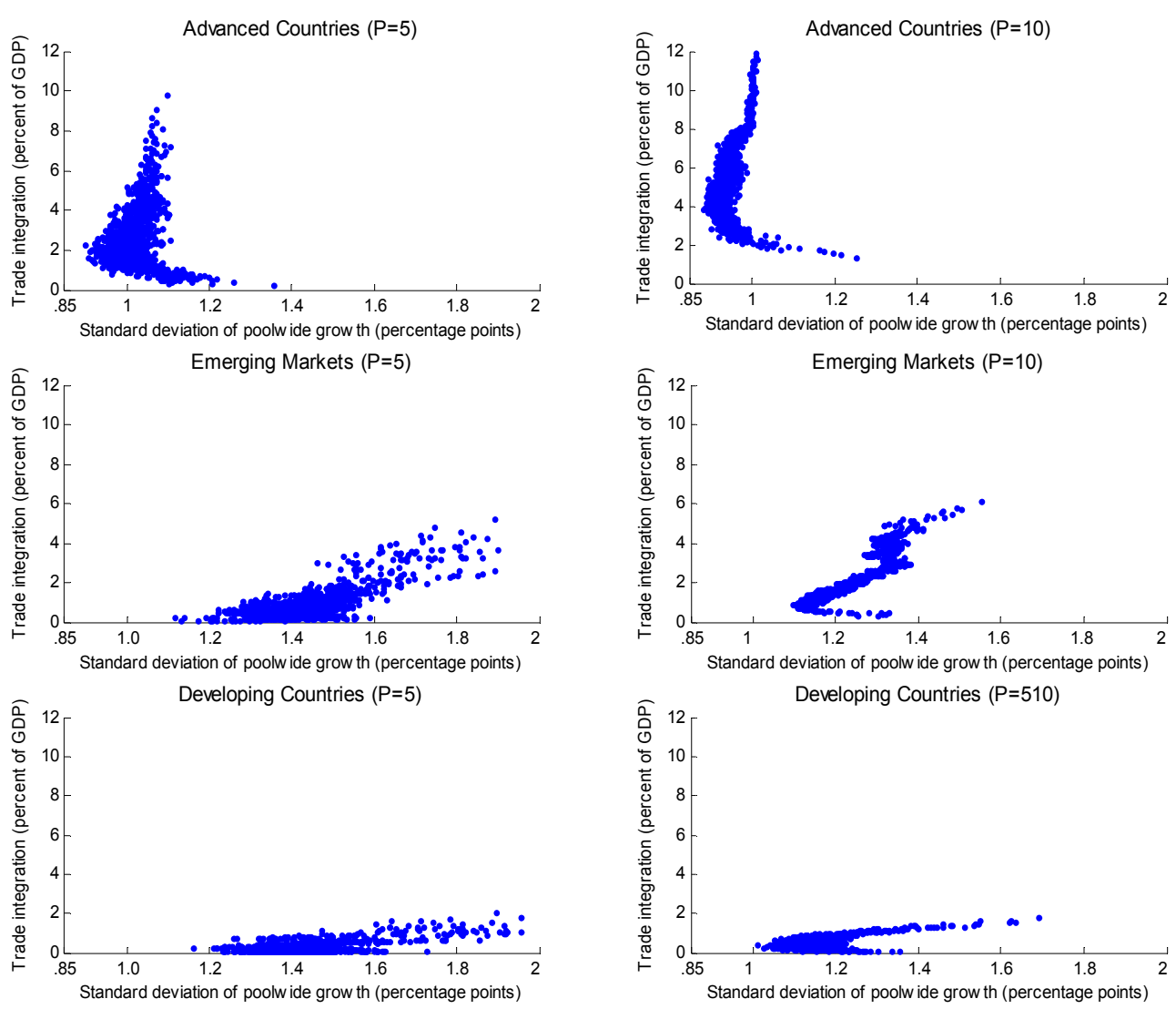

Notes: The scatter plots report poolwide trade integration and the standard deviation of the growth rate of aggregate (poolwide) GDP for all pools of sizes 5 and 10 (as indicated) drawn from the subsamples indicated. Trade integration is the sum (across pool members) of exports to other pool members, divided by poolwide GDP. To compute trade integration, the data on exports (in US\$ at current prices) are from the International Monetary Fund's Direction of Trade Statistics, and the data on GDP (in US\$ at current prices) are from the IMF's World Economic Outlook database. To compute growth volatility, GDP data (PPP) are from the World Bank's World Development Indicators.

\section{F. Existing Arrangements}

Finally, we consider the potential welfare gains arising from existing risk-sharing arrangements such as the Chiang-Mai Initiative or FLAR. We also discuss other types of international agreements, whereby participants have long-established cooperation, for example, in the context of a currency union or a trade agreement. We then compare such gains to those that the participant countries would be able to obtain in pools of the same size, drawing their partners from the whole, unconstrained sample. The objective here is not to assess the desirability of the membership structure of existing arrangements, but rather to estimate the value of wellestablished relations of trust, which make it possible to sustain risk-sharing arrangements. 
We find that existing risk-sharing and other types of arrangements have the potential to yield substantial welfare gains. At the same time, we see that diversifying outside of existing groups has the potential to yield considerably greater welfare gains.

Table 5 notes the median (first row) and minimum (second row) standard deviation of individual growth rates (across participants in the agreements indicated) and compares them with the standard deviation of poolwide growth obtained by pooling with other members of the existing arrangement (third row) or by joining the best possible pool of the same size as the existing arrangement but chosen within the whole universe of countries (fourth row). Substantial gains appear to be available even for the least volatile countries in each arrangement. For the existing groups considered, poolwide volatility is lower than that of each individual member's (with the exception of FLAR). The median standard deviation of poolwide growth (across members) in the optimal pool of the same size as the existing arrangement, but with unconstrained membership, is half or less of than volatility under autarchy. The last two rows suggest that enforcement considerations play a major role because they seem to outweigh potentially large diversification gains.

\section{EXTENSIONS}

In this section, we extend our approach in three directions. First, we allow expected growth rates to differ across countries. Second, we maintain our focus on the sharing of GDP risk, but ask a slightly different question. Thus far, we have assumed that pool members would share their entire output streams. Now we ask which country grouping yields the greatest risk diversification benefits for a given absolute size of the risk sharing contract, for example, a US\$1 contract, or a US\$1 billion contract. Third, recognizing that many past, existing, and proposed arrangements are motivated by a desire to contain liquidity or exchange rate crises, we ask which country groupings are least likely to have more than one country in crisis at the same time.

\section{A. Pooling Growth Rates}

In our baseline approach, we have assumed that expected growth rates are the same for all countries. In principle, countries with relatively high expected growth rates should be able to obtain a higher share of poolwide consumption. In reality, however, the great practical challenges involved in predicting growth rates beyond the subsequent few years would make it relatively difficult to incorporate differences in expected growth in the terms of risk sharing contracts. ${ }^{37}$ As shown by Easterly and others (1993), country rankings with respect to growth rates change dramatically from one decade to the next. Similarly, Jones and Olken (2005) document that most countries experience both growth miracles and failures at some point in

\footnotetext{
${ }^{37}$ Our main interest in this paper relates to the choice of country groupings rather than the optimal design of the risk sharing contract. Nevertheless, further research could explore contracts that allow countries to change the shares of poolwide income they receive, say, each year, as expected growth rates are updated in the light of new information.
} 
Table 5. Poolwide Volatility for Selected Groups

\begin{tabular}{lccccccccc}
\hline & APEC & ASEAN & CHIANG MAI & ECOWAS & EMU & EU & FLAR & MERCOSUR & NAFTA \\
\hline$\sigma_{\text {median }}^{\text {indidial }}$ & 3.73 & 4.36 & 3.93 & 4.58 & 1.78 & 1.77 & 4.00 & 4.33 & 2.11 \\
$\sigma_{\text {min }}^{\text {individual }}$ & 2.00 & 3.65 & 2.01 & 3.07 & 1.36 & 1.36 & 2.19 & 3.51 & 2.00 \\
$\sigma_{\text {pool }}$ & 1.29 & 3.47 & 1.40 & 2.19 & 1.19 & 1.11 & 2.48 & 3.09 & 1.81 \\
$\sigma_{\begin{array}{l}\text { unconstr } \\
\text { median }\end{array}}$ & 0.68 & 0.86 & 0.79 & 0.72 & 0.66 & 0.65 & 0.71 & 0.74 & 1.16 \\
\hline
\end{tabular}

Notes: The first (second) row reports the median (minimum) standard deviation of individual country GDP growth across countries in the group indicated. The third row is poolwide volatility for the group. The fourth row is the median across countries in the group of poolwide volatility for the best pool (of the same size as the group indicated). The groups are the AsiaPacific Economic Cooperation (APEC), the Association of South East Asian Nations (ASEAN), the Chiang Mai Initiative (CHIANG MAI), the Economic Community of West African States (ECOWAS), the European Monetary Union (EMU), the European Union (EU), the Latin American Reserve Fund (FLAR), Mercado Común del Sur (Mercosur), and the North American Free Trade Agreement (NAFTA).

their history. It is unlikely that the parties negotiating the terms of a risk sharing agreement would be able to come to a common view of their countries' relative future growth performance. And the size of the upfront transfers involved might preclude an agreement. One might even argue that this is a further important reason underlying the limited extent to which risk sharing arrangements occur in practice among sovereign nations.

Despite these caveats, we now extend the analysis to the case where expected growth rates can differ across countries. To estimate expected economic growth, we simply consider average growth over the entire period under consideration, namely $1975-2004 .{ }^{38}$ Possible alternative approaches include using the predicted growth rate from cross-country or panel growth regressions, along the lines of van Wincoop (1999) for instance. This would tend to lead to lower diversity in expected economic growth. To emphasize the implications of introducing differences in expected growth in the analysis, we report findings based on a naïve averaging of past growth rates.

Table 6 reports the welfare gains obtained for the case where all 74 countries in our sample pool together and for the cases where advanced economies, emerging markets, and developing countries each pool among themselves. Compared with the setup where expected growth is assumed to be the same for all countries (Table 3), the welfare gains are somewhat larger in

\footnotetext{
${ }^{38}$ The analysis also assumes that individual countries' growth rates are unaffected by pooling arrangements. A possible concern might be that lower volatility in a pool might come at the expense of lower mean growth. However, this would seem unlikely, in light of evidence that low volatility countries tend to have high mean growth (Ramey and Ramey, 1995; and Martin and Rogers, 2001), though volatility and growth rates are positively associated in sectoral data (Imbs, 2006; and Acharya and Imbs, 2006).
} 


\section{Table 6. Welfare Gains Allowing for "Entry Transfers" and Differences in Expected Growth \\ (percent of annual consumption)}

\begin{tabular}{|c|c|c|c|}
\hline & Minimum Gain & Median Gain & $\begin{array}{l}\text { Gains as a Share of Initial } \\
\text { GDP for Sub-Sample } \\
\text { Indicated }\end{array}$ \\
\hline Full Sample & $\begin{array}{c}0.37 \\
\text { United States }\end{array}$ & $\begin{array}{c}5.84 \\
\text { Costa Rica }\end{array}$ & 5.93 \\
\hline Advanced Countries & $\begin{array}{l}0.42 \\
\text { Italy }\end{array}$ & $\begin{array}{c}1.22 \\
\text { Denmark }\end{array}$ & 1.18 \\
\hline Emerging Markets & $\begin{array}{l}1.74 \\
\text { Tunisia }\end{array}$ & $\begin{array}{c}6.86 \\
\text { Malaysia }\end{array}$ & 9.82 \\
\hline Developing Countries & $\begin{array}{c}1.08 \\
\text { Guatemala }\end{array}$ & $\begin{array}{c}7.41 \\
\text { Malawi }\end{array}$ & 9.86 \\
\hline \multicolumn{4}{|c|}{$\begin{array}{l}\text { Notes: Minimum, median, and total welfare gains for subsamples indicated. Computed allowing for the possibility } \\
\text { of "entry transfers," but assuming the same expected growth across countries. The results assume } \theta=2, \gamma=5 \text {, and } \\
\beta=0.95 \text {. Expected growth rates are assumed to equal those over the period } 1975-2004 \text {. The list of subsamples is } \\
\text { provided in Appendix Table 1. GDP data are drawn from the World Bank's World Development Indicators. }\end{array}$} \\
\hline
\end{tabular}

\section{B. Best Marginal Contract}

Here we ask which pool of countries provides the greatest risk diversification benefits for a given US\$1 GDP risk sharing contract. This is equivalent to repeating the analysis in previous sections focusing on an unweighted average of the growth rates of the various hypothetical members, rather than the weighted average that is the growth rate of aggregate GDP. This presents a major advantage from the standpoint of computational ease and accuracy. In fact, finding the lowest unweighted average of the growth rates is a variant of the Traveling Salesman's problem, well known in computer science, for which approximate solutions have been developed. Applying the Han, Ye, and Zhang (2002) method to our problem yields the results summarized in Figure 7. 


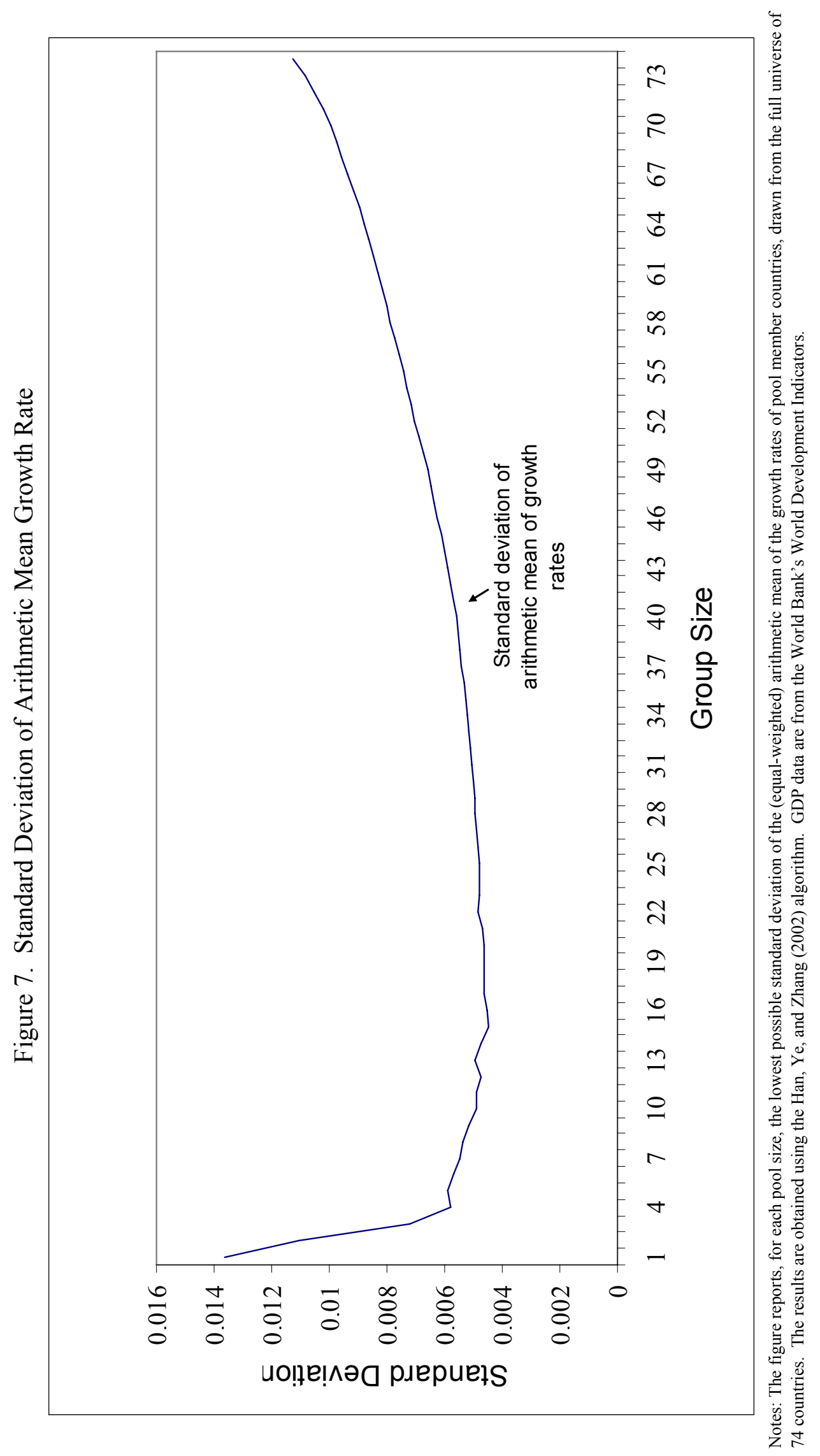


Our results are strengthened. The global envelope reaches a minimum corresponding to a pool of size $20 .{ }^{39}$ Again, most of the risk sharing gains are exhausted quickly, with small size pools. A pool as small as size 4 (Austria, Colombia, New Zealand, and Spain) is already close to the overall best.

\section{Liquidity-Crisis Based Criteria}

We have referred to international reserve-pooling arrangements that are aimed at protecting participants from liquidity or exchange-rate crises. In this section, we focus more specifically on the question of which pools minimize the likelihood of exchange rate pressure episodes taking place in a number of participant countries at the same time.

Our definition of exchange rate pressure episodes is standard. We construct an index as the simple average of the normalized (i) exchange rate depreciation and (ii) international reserves decline. To normalize each series, we compute the mean and the standard deviation over the (rolling) window of the previous 60 months; from each observation, we then subtract the mean, and divide by the standard deviation. Exchange rate pressure occurs (and our binary variable takes value one) when the exchange rate pressure index exceeds 10 in one month or 4 on average over a three-month period.

To gauge the likelihood that "undiversifiable" exchange pressures would arise within a given pool, we compute the number of months during which exchange rate pressure is experienced by countries that together account for more than 30 percent of poolwide output. For a given pool of countries, for each of the 360 months in the sample period (1975-2004), we identify the countries experiencing exchange rate pressure either during the month under consideration or within a 12-month window around it. We next assess whether the sum of the GDPs of the countries experiencing exchange rate pressure exceeds 30 percent of total poolwide output. Finally we compute the total number of months during which more than 30 percent of poolwide output is affected. ${ }^{40}$ Using this criterion, we run our algorithm on the universe of emerging markets to find, for each pool size, the pools that yield the lowest measure of "common exchange rate pressures" as defined above.

The results are reported in Table 7. We seek to gauge the extent to which contemporanous exchange rate pressures are likely to be experienced within pools constrained to be formed within regions, as compared with pools where cross-regional participation is permitted. For each pool size, we therefore report the best pools and the corresponding number of months with "undiversifiable" exchange rate pressures. As before, we constrain the samples in a variety of ways, first with the universe of all emerging markets, and then its Latin American and Asian components.

\footnotetext{
${ }^{39}$ Australia, Austria, Bangladesh, Bolivia, Cameroon, China, Colombia, Costa Rica, France, Gambia, Korea (Republic of), New Zealand, Pakistan, Senegal, Singapore, Spain, Sweden, Switzerland, Syria, and Tunisia.

${ }^{40}$ The results are similar with a threshold of 20 percent of GDP.
} 
38
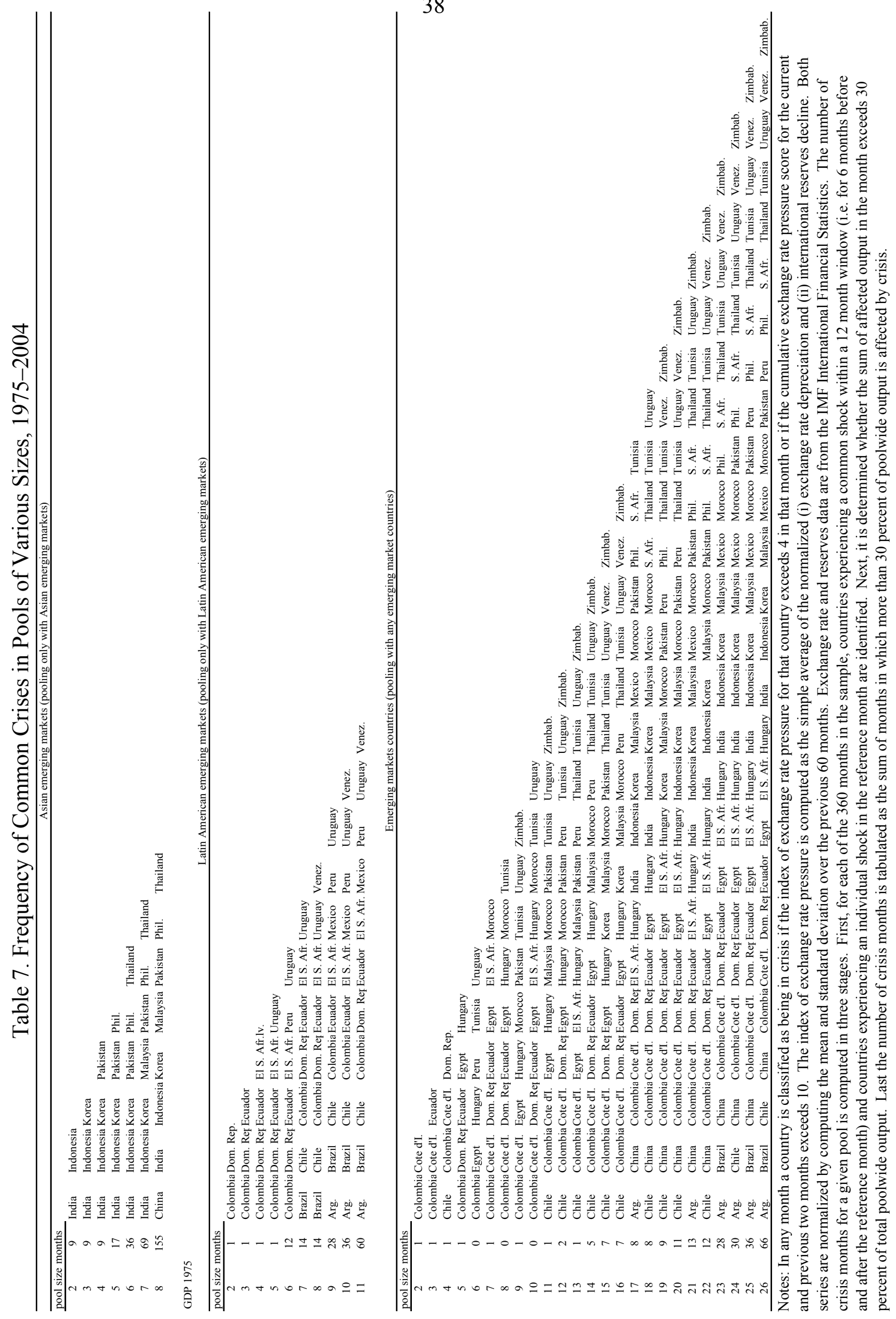
The findings suggest that regional constraints are even more important when examining episodes of exchange rate pressure than for the sharing of output growth risk. The number of months when "undiversifiable" exchange rate pressures are experienced is far lower when the best pool is constructed from the whole universe of emerging markets rather than from regional samples. At pool size 7, for instance, the number of months with "undiversifiable" crises for the best pool is 1 for the best pool drawn from the universe of all emerging markets, but 14 for the best Latin American pool and 69 for the best Asian pool. This finding is broadly in line with studies that find a substantial regional element in currency crises and in international contagion more generally (Glick and Rose, 1999). ${ }^{41}$

\section{Conclusion}

Although the potential benefits of international risk sharing have long been the subject of debate, existing studies have focused on the benefits that an individual country would draw from greater financial integration into the world economy. Full global financial integration has hitherto proved elusive, presumably owing in part to limited contract enforcement and monitoring costs. Monitoring and enforcement may be easier within smaller groups of countries, and we have shown that risk sharing pools involving a handful of economies can often provide substantial welfare gains. Then the question of which countries to pool with becomes of the essence, and our paper has provided a systematic analysis of which pools of countries would provide the greatest risk sharing benefits, under various possible constraints on membership.

Even though they rely on a standard theoretical framework, our findings suggest that the welfare benefits of international risk sharing can be substantial, and achievable among surprisingly few countries. If these gains can be achieved within pools consisting of only a handful of countries, why are risk sharing arrangements, in one guise or another, not more widespread? We conjecture that contract enforceability imposes major constraints on the country pools that may emerge in practice. We show that potential welfare gains are relatively small among the universe of countries with relatively strong institutions and unblemished repayment records. In a few cases, pools formed on a regional basis, or built upon pre-existing political, economic or trade relationships can provide substantial diversification gains. This is consistent with the observation that the few existing pools, or those under discussion, tend to involve a regional element or pre-existing well-established relations. But again, we have shown that risksharing opportunities are considerably lower when the choice of one's partners is constrained, for example, geographically.

\footnotetext{
${ }^{41}$ The general message holds with alternative definitions of common crises, which we do not report for the sake of brevity. We considered for instance all pairs of countries within any given pool, computed the ratio of pairwise common episodes of exchange rate pressure to the sum of all episodes, and then computed the average of such ratio over all possible pairs of countries within the pool. The results are virtually identical to those reported in Table 7.
} 
On the whole, samples where enforceability may be easier also tend to provide smaller diversification opportunities, so that arrangements to pool risk may not be worthwhile. More generally, international risk sharing may be limited not because the gains it affords are too small to matter, but rather because contract enforcement may be difficult exactly where risk sharing gains would be largest. 


\section{APPENDiX: “Stable” PoOls Based on Volatility CRiterion}

In this appendix, we pursue the analysis of "stable" pools, which — based on a pure volatility criterion - we define as those in which all proposed members would be willing to participate. In particular, we seek groups whose total membership would not be better off in alternative pools, on the basis of risk diversification gains only. This question can be asked either holding the pool size fixed, or allowing pool sizes to vary. In what follows, we present the results of both exercises.

We use the following procedure. Without imposing participation by any specific country, we identify the pool that provides the lowest standard deviation of poolwide growth. We note the participants in this necessarily stable pool. We then exclude them from the sample and repeat the exercise, which identifies the participants in a second (somewhat worse off) stable pool. We iterate the procedure. In some cases there will be a few countries that cannot find room in a stable pool. ${ }^{42}$

We begin with the case where pool sizes are exogenously given and conduct the exercise for each possible pool size. Appendix Figure 1 reports the standard deviation of the poolwide growth rate of the stable groups, for each pool size. For example, at pool size 2 there are 37 stable pools with volatility ranging from 1.10 percentage point (Austria and New Zealand) to 8.91 percentage point (Gabon and Rwanda). Pool size 7 is the last we analyze, due to computational constraints, and there are 10 stable pools with volatility ranging from 0.6 percentage point to 2.5 percentage points.

Although many of the stable pools have volatilities well above those provided by the best pool to its members, the gains are typically large for most countries, with a minimum of 0.2 percentage point even at pool size 2, and average (or median) declines somewhere between 0.9 and 2.7 percentage point (see text table below).

\begin{tabular}{lcccrrr}
\hline \multicolumn{7}{c}{$\begin{array}{l}\text { Volatility Reduction from Joining a Stable Pool } \\
\text { (percentage points) }\end{array}$} \\
\hline Pool Size & $\mathbf{2}$ & $\mathbf{3}$ & $\mathbf{4}$ & \multicolumn{1}{c}{$\mathbf{5}$} & \multicolumn{1}{c}{$\mathbf{6}$} & $\mathbf{7}$ \\
\hline Minimum & 0.19 & 0.22 & 0.22 & 0.22 & 0.29 & 0.22 \\
Maximum & 9.18 & 10.69 & 10.88 & 11.27 & 11.27 & 10.90 \\
Average & 1.41 & 2.09 & 2.37 & 2.53 & 2.69 & 2.62 \\
Median & 0.91 & 1.58 & 1.91 & 2.15 & 2.24 & 2.32 \\
& & & & & & \\
\hline
\end{tabular}

The more general exercise is to find the set of stable pools without restricting pool size. We know from previous sections the identity of the best stable pool of 17 countries. We take them out of the sample, look for the best pool among the remaining countries and find that it consists

\footnotetext{
${ }^{42}$ This usually happens in exercises where the size of the pool is fixed and the residual sample is smaller.
} 
of the 19 countries listed in the text table below, with volatility of 0.72 percentage point. By iterating, we find a third stable pool of 14 countries ( 0.90 percentage point), a fourth of 13 countries ( 1.46 percentage point), a fifth of 7 countries ( 1.98 percentage point), and a sixth of 3 countries (3.28 percentage point). One country is left on its own (even though it is not the most volatile individually). Despite the lack of realism of this exercise, an interesting point that comes through is that each of the first five stable pools includes a mix of advanced countries, emerging markets, and developing countries, and from essentially all continents.

Stable Pools (Unrestricted Size) Drawing from Full Universe of 74 Countries

\begin{tabular}{|c|c|c|}
\hline Pool Size & $\begin{array}{l}\text { Standard } \\
\text { Deviation } \\
\text { (percent) }\end{array}$ & Members \\
\hline 17 & 0.50 & $\begin{array}{l}\text { Austria, Benin, Cameroon, Colombia, Costa Rica, Dominican Republic, El Salvador, } \\
\text { Gambia, Ghana, Kenya, New Zealand, Nicaragua, Senegal, Sweden, Syria, Tunisia, } \\
\text { Zimbabwe }\end{array}$ \\
\hline 19 & 0.72 & $\begin{array}{l}\text { Algeria, Argentina, Australia, Bangladesh, Bolivia, Republic of Congo, Denmark, } \\
\text { France, India, Italy, Korea, Malawi, Mexico, Netherlands, Norway, Pakistan, Peru, } \\
\text { Rwanda, Switzerland }\end{array}$ \\
\hline 14 & 0.90 & $\begin{array}{l}\text { Belgium, Canada, China, Egypt, Finland, Gabon, Germany, Hungary, Iceland, Japan, } \\
\text { Philippines, Portugal }\end{array}$ \\
\hline 13 & 1.46 & $\begin{array}{l}\text { Botswana, Chile, Ecuador, Greece, Guatemala, Hong Kong SAR, Ireland, Morocco, } \\
\text { Paraguay, Singapore, Trinidad and Tobago, United Kingdom, Uruguay }\end{array}$ \\
\hline 7 & 1.98 & Brazil, Cote d'Ivorie, Indonesia, Luxembourg, Madagascar, Thailand, United States \\
\hline 3 & 3.28 & Malaysia, Togo, Venezuela \\
\hline Remainder & & Lesotho \\
\hline
\end{tabular}




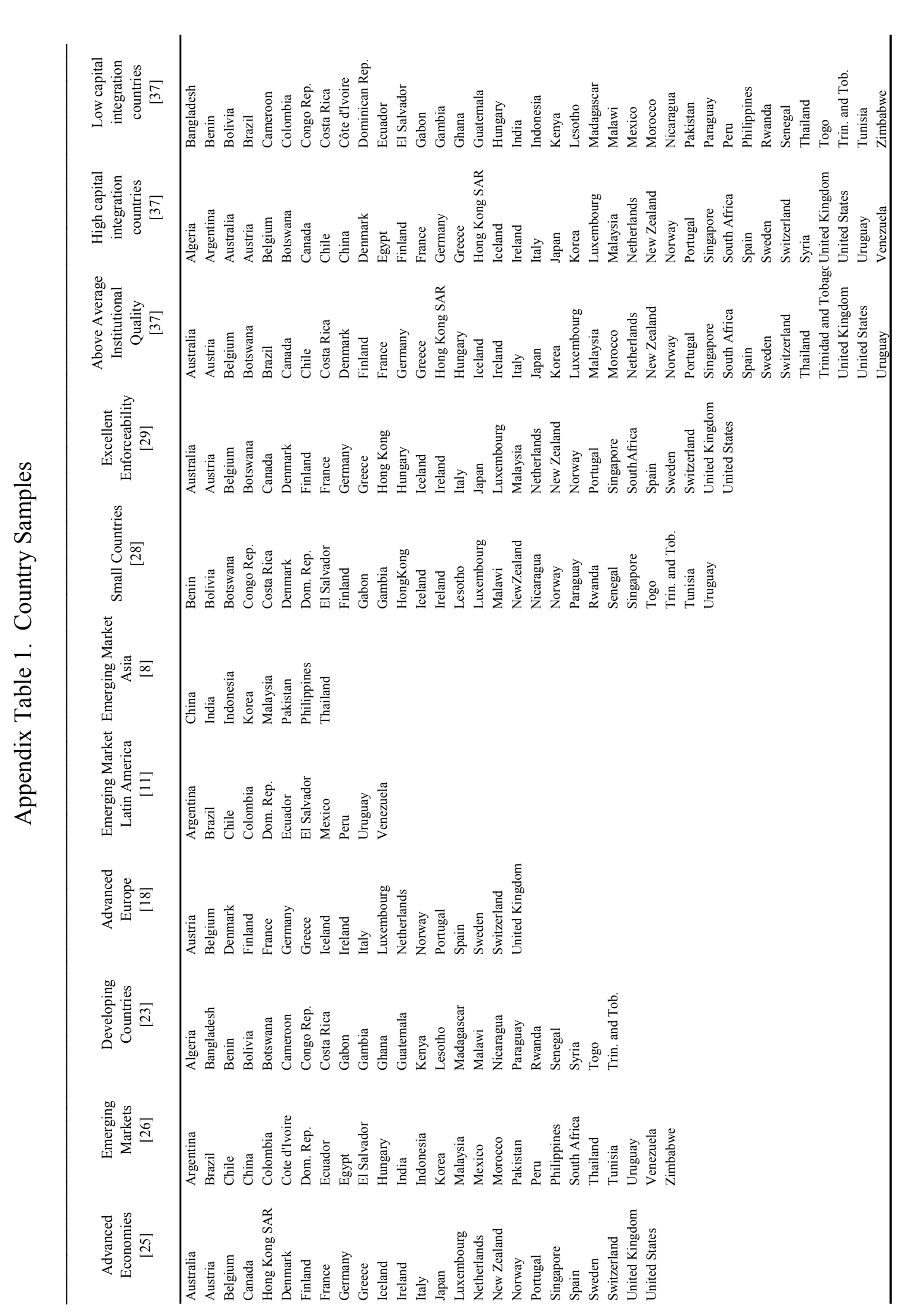

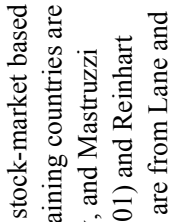

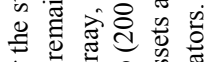

可

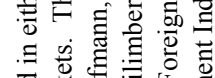

월

을 论

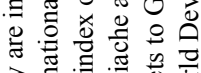

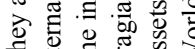

.

on 000

흘

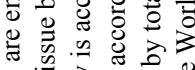

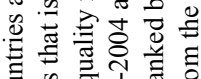

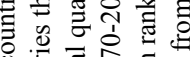

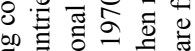

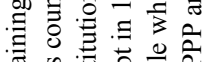

웡

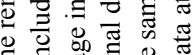

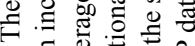

을 을 형

잉

亏ิ

的鱼

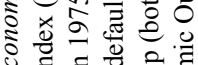

의

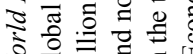

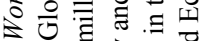

w

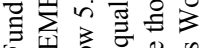

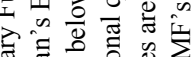

of

흥을

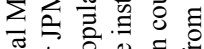

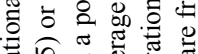

政

व 3

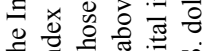

政

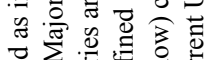

政

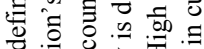

팡 $\overline{2}$

造论

言 .

政

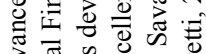

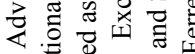

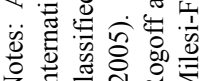




\section{Appendix Table 2. Lowest Standard Deviation of Poolwide Growth Choosing Pools Under Various Constraints}

\begin{tabular}{|c|c|c|c|c|c|c|c|}
\hline \multirow[t]{2}{*}{ For Typical Country in Group (Median $\sigma$ across countries in the group) } & \multicolumn{7}{|c|}{ Pools always include country in question } \\
\hline & $\begin{array}{l}\sigma \text { individual } \\
\text { country } \\
\text { alone } \\
\end{array}$ & $\begin{array}{l}\sigma \text { Best Pool } \\
\text { of } 2 \\
\text { countries }\end{array}$ & $\begin{array}{l}\sigma \text { Best Pool } \\
\text { of } 3 \\
\text { countries }\end{array}$ & $\begin{array}{l}\sigma \text { Best Pool } \\
\text { of } 5 \\
\text { countries }\end{array}$ & $\begin{array}{l}\sigma \text { Best Pool } \\
\text { of } 7 \\
\text { countries }\end{array}$ & $\begin{array}{l}\sigma \text { Best Pool } \\
\text { of } 10 \\
\text { countries }\end{array}$ & $\begin{array}{l}\sigma \text { Best Pool } \\
\text { of any size }\end{array}$ \\
\hline All countries (pooling with any country) & 3.62 & 1.33 & 1.08 & 0.82 & 0.68 & 0.58 & 0.54 \\
\hline \multicolumn{8}{|l|}{ Interest in risksharing, by level of development, size } \\
\hline Advanced (pooling with any country) & 2.01 & 1.28 & 1.08 & 0.87 & 0.74 & 0.65 & 0.62 \\
\hline Advanced (pooling only with advanced) & 2.01 & 1.28 & 1.10 & 0.95 & 0.91 & 0.89 & 0.89 \\
\hline Emerging (pooling with any country) & 4.01 & 1.34 & 1.10 & 0.89 & 0.78 & 0.70 & 0.61 \\
\hline Emerging (pooling only with emerging) & 4.01 & 2.05 & 1.61 & 1.29 & 1.19 & 1.12 & 1.07 \\
\hline Developing (pooling with any country) & 5.15 & 1.36 & 1.09 & 0.80 & 0.66 & 0.54 & 0.51 \\
\hline Developing (pooling only with developing) & 5.15 & 1.93 & 1.63 & 1.34 & 1.16 & 1.05 & 1.01 \\
\hline Small countries (pooling with any country) & 4.50 & 1.35 & 1.08 & 0.80 & 0.66 & 0.55 & 0.51 \\
\hline Small countries (pooling only with small countries) & 4.50 & 1.72 & 1.36 & 1.07 & 0.96 & 0.89 & 0.87 \\
\hline \multicolumn{8}{|l|}{ Costs of regional constraints } \\
\hline European Union (pooling only with advanced) & 1.84 & 1.27 & 1.10 & 0.95 & 0.91 & 0.89 & 0.89 \\
\hline European Union (pooling only with EU) & 1.84 & 1.27 & 1.17 & 1.08 & 1.05 & 1.06 & 1.05 \\
\hline Asian emerging (pooling only with emerging) & 3.62 & 2.29 & 1.69 & 1.37 & 1.23 & 1.15 & 1.09 \\
\hline Asian emerging (pooling only with Asian emerging) & 3.62 & 2.40 & 2.21 & 1.92 & 1.84 & n.a & 1.84 \\
\hline Latin American emerging (pooling only with emerging) & 4.41 & 2.00 & 1.61 & 1.28 & 1.19 & 1.12 & 1.07 \\
\hline Latin American emerging (pooling only with Latin American emerging) & 4.41 & 2.34 & 2.06 & 1.90 & 2.20 & 2.36 & 1.90 \\
\hline \multicolumn{8}{|l|}{ Costs of weak enforcement } \\
\hline Excellent enforceability countries (pooling with any country) & 2.11 & 1.28 & 1.08 & 0.87 & 0.74 & 0.65 & 0.61 \\
\hline Excellent enforceability countries (pooling only with excellent enforceability countries) & 2.11 & 1.28 & 1.10 & 0.95 & 0.90 & 0.87 & 0.87 \\
\hline Emerging and developing country excellent enforce. (pooling with any excellent enforce.) & 4.08 & 1.31 & 1.10 & 0.96 & 0.91 & 0.87 & 0.87 \\
\hline Emerg. and dev. excellent enforce. (pooling only with emerg. and dev. excellent enforce.) & 4.08 & 2.41 & 2.25 & n.a. & n.a. & n.a. & 2.25 \\
\hline Above average institutional quality (pooling with any country) & 2.61 & 1.29 & 1.09 & 0.87 & 0.73 & 0.65 & 0.61 \\
\hline Above average inst. countries (pooling with only above average inst. countries) & 2.61 & 1.29 & 1.10 & 0.94 & 0.89 & 0.85 & 0.82 \\
\hline Above average inst. emerg. and dev. country (pooling with any above average inst. country) & 4.38 & 1.34 & 1.10 & 0.86 & 0.72 & 0.63 & 0.59 \\
\hline Above average inst. emerg. and dev. (pooling only with above average inst. emerg. and dev.) & 4.38 & 2.36 & 2.01 & 1.74 & 1.64 & 1.76 & 1.64 \\
\hline \multicolumn{8}{|l|}{ Current degree of international financial integration } \\
\hline High integration countries (pooling only with high integration countries) & 2.61 & 1.29 & 1.09 & 0.90 & 0.83 & 0.76 & 0.74 \\
\hline Low integration countries (pooling only with low integration countries) & 4.36 & 1.93 & 1.44 & 1.09 & 0.92 & 0.80 & 0.76 \\
\hline
\end{tabular}

Notes: The table reports the median (across countries in each sub-sample as indicated) of the lowest possible standard deviation of pool wide growth, at various pool sizes. The list of subsamples is provided in Appendix Table 1. Small Countries are those with a total 1970 population of less than 5.2 million. Above average institutional quality is according to the index of Kaufmann, Kraay, and Mastruzzi (2005). Excellent enforceability is defined as above average institutional quality and no defaults on international debt in 1970-2004 according to Detragiache and Spilimbergo (2001), and Reinhart Rogoff and Savastano (2003). High (low) capital integration countries are those in the top (bottom) half of the sample when ranked by total foreign assets to GDP. (Foreign assets are from Lane and Milesi-Ferretti, 2006; GDP data in current U.S. dollars are from the IMF's World Economic Outlook.) GDP data at PPP are from the World Bank's World Development Indicators. 


\section{Appendix Table 3. Welfare Gains for Different Groups of Countries Under Various Constraints}

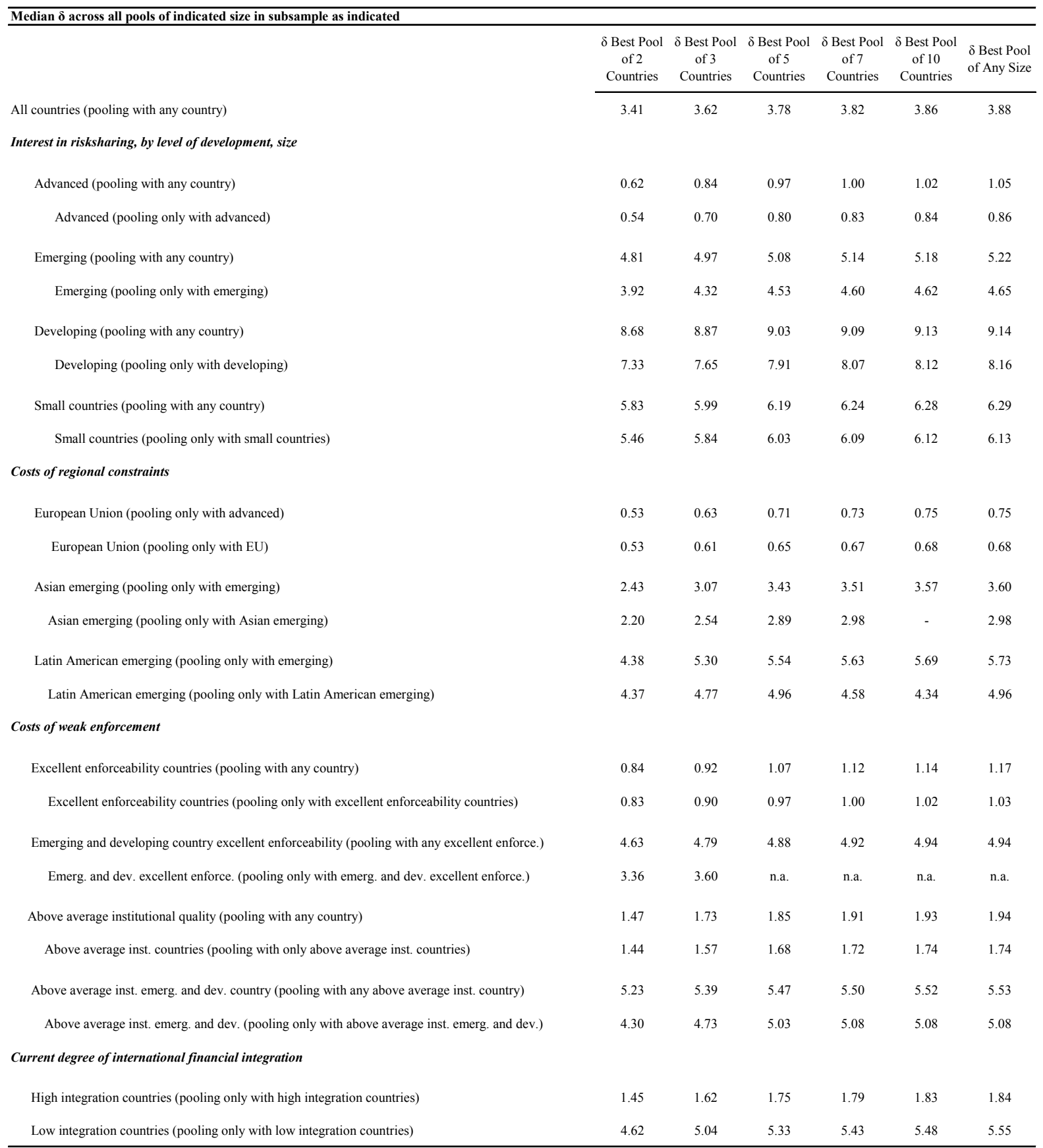

Notes: The table reports the median welfare gain (across countries in the subsample as indicated) obtained by entering the best possible pool (of each size, as indicated) drawn from the subsample as stated. Welfare gains are computed under the assumption of equal expected growth across countries and no "entry ticket" payments. The list of subsamples is provided in Appendix Table 1. Small countries are those with a total 1970 population of less than 5.2 million. Above average institutional quality is according to the index of Kaufmann, Kraay, and Mastruzzi (2005). Excellent enforceability is defined as above average institutional quality and no defaults on international debt in 1970-2004 according to Detragiache and Spilimbergo (2001), and Reinhart Rogoff and Savastano (2003). High (low) capital integration countries are those in the top (bottom) half of the sample when ranked by total foreign assets to GDP. (Foreign assets are from Lane and Milesi-Ferretti, 2006; GDP data in current U.S. dollars are from the IMF's World Economic Outlook.) GDP data at PPP are from the World Bank's World Development Indicators. 


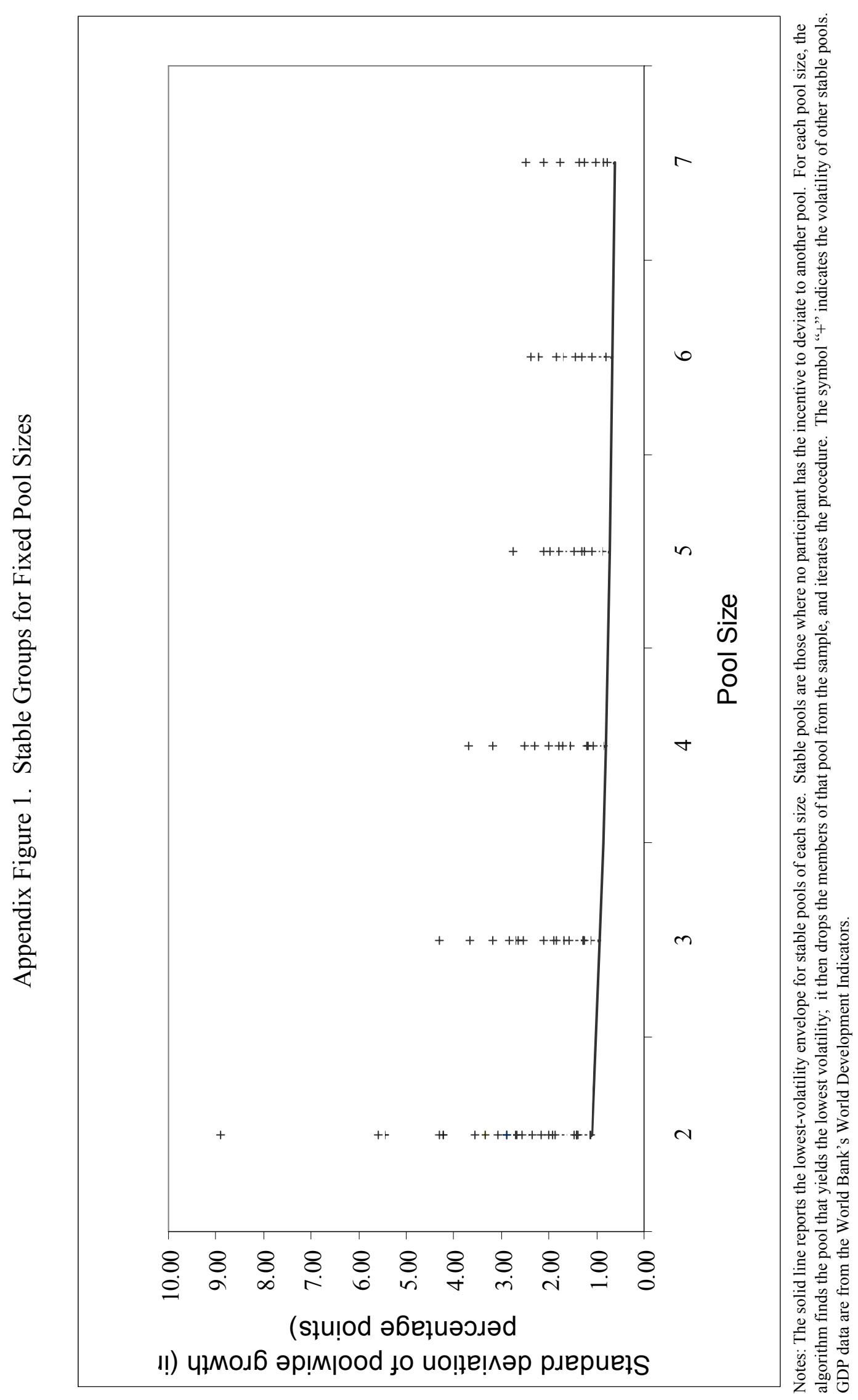




\section{REFERENCES}

Aguiar, Mark, and Gita Gopinath, forthcoming, "Emerging Market Business Cycles: The Cycle is the Trend," Journal of Political Economy.

Alesina, Alberto, and Robert J. Barro, "Currency Unions," Quarterly Journal of Economics, Vol. 107, No. 2, pp. 409-436.

Alesina, Alberto, Robert J. Barro, and Silvana Tenreyro, 2003, "Optimal Currency Areas," NBER Macroeconomics Annual 2002, Vol. 17, pp. 301-345 (Cambridge, Massachusetts and London: MIT Press).

Alfaro, Laura, Sebnem Kalemli-Ozcan, and Vadym Volosovych, 2005, "Capital Flows in a Globalized World: the Role of Policies and Institutions," NBER Working Paper 11696 (Cambridge, Massachusetts: National Bureau of Economic Research).

Athanasoulis, Stefano G., and Eric van Wincoop, 2000, "Growth Uncertainty and Risksharing," Journal of Monetary Economics, Vol. 45, pp. 477-505.

Backus, David K., Patrick J. Kehoe, and Finn E. Kydland, 1994, "Dynamics of the Trade Balance and the Terms of Trade: The J-curve?" American Economic Review, pp. 84-103.

Backus, David K., and Gregor W. Smith, 1993, "Consumption and real exchange rates in dynamic economies with non-traded goods," Journal of International Economics, November, Vol. 35, No. 3-4, pp. 297-316.

Barlevy, Gadi, 2004, "The Cost of Business Cycles under Endogenous Growth," American Economic Review, September, Vol. 94, No. 4, pp. 964-990.

Barro, Robert, 2007, "On the Welfare Costs of Consumption Uncertainty," mimeo Harvard University.

Baxter, Marianne, and Michael A. Kouparitsas, 2005, "Determinants of business cycle comovement: a robust analysis,” Journal of Monetary Economics, January, Vol. 52, No. 1, pp. 113-157.

Bayoumi, Tamim, and Barry Eichengreen, 1994, "One Money or Many? Analyzing the Prospects for Monetary Unification in Various Parts of the World," Princeton Studies in International Finance, No. 76. 
Bayoumi, Tamim, and Barry Eichengreen, 1998, "Exchange Rate Volatility and Intervention: Implications of the Theory of Optimum Currency Areas," Journal of International Economics, Vol. 45, pp. 191-209.

Borensztein, Eduardo R., and Paolo Mauro, 2004, "The Case for GDP-Indexed Bonds," Economic Policy, April, Vol. 19, No. 38, pp. 165-216.

Cole, Harold L., and Obstfeld, Maurice, 1991, "Commodity trade and international risk sharing: How much do financial markets matter?" Journal of Monetary Economics, August, Vol. 28, pp. 3-24.

Detragiache, Enrica, and Antonio Spilimbergo, 2001, "Crises and Liquidity-Evidence and Interpretation,” IMF Working Paper 01/02 (Washington: International Monetary Fund).

Dezhbakhsh, Hashem, and Daniel Levy, 2003, "On the typical spectral shape of an economic variable," Applied Economics Letters, May, Vol. 10, No. 7, pp. 417-423.

Eichengreen, Barry, 2006, "Insurance Underwriter or Financial Development Fund: What Role for Reserve Pooling in Latin America?” NBER Working Paper 12451 (Cambridge, Massachusetts: National Bureau of Economic Research).

Eichengreen, Barry, and Charles Wyplosz, 1993, "The Unstable EMS," Brookings Papers on Economic Activity, No. 1, pp. 51-143.

Frankel, Jeffrey A, and Andrew K. Rose, 1998, "The Endogeneity of the Optimum Currency Area Criteria,” Economic Journal, July, Vol. 108, No. 449, pp. 1009-25.

Glick, Reuven, and Andrew K. Rose, 1999, "Contagion and Trade: Why are currency crises regional?" Journal of International Money and Finance, Vol. 18, pp. 603-617.

Han, Qiaoming, Yinyu Ye, and Jiawei Zhang, 2002, “An Improved Rounding Method and Semidefinite Programming Relaxation for Graph Partition," Mathematical Programming, Vol. 92, No. 3, pp. 509-535.

Imbs, Jean, 2004, “Trade, Finance, Specialization and Synchronization," Review of Economics and Statistics, August, Vol. 86, No.3.

Imbs, Jean, 2006, "The Real Effects of Financial Integration," Journal of International Economics, March, Vol. 68, No. 2, pp. 296-324. 
Kaufmann, Daniel, Aart Kraay, and Massimo Mastruzzi, 2005, "Governance Matters IV: Governance Indicators for 1996-2004,” The World Bank, http://www.worldbank.org/wbi/governance/govdata/.

Kehoe, P., and F. Perri, 2002, "International business cycles with endogenous incomplete markets," Econometrica, Vol. 70, pp. C907-C28.

Easterly, William, Michael Kremer, Lant Pritchett, and Lawrence H. Summers, 1993, "Good policy or good luck? Country growth performance and temporary shocks," Journal of Monetary Economics, Vol. 32, pp. 459-483.

Jones, Benjamin, and Benjamin Olken, 2005, “The Anatomy of Start-Stop Growth,” NBER Working Paper No. 11528 (Cambridge, Massachusetts: National Bureau of Economic Research).

Lewis, Karen K., 1996, "Consumption, Stock Returns, and the Gains from International Risk-Sharing," NBER Working Paper W5410 (Cambridge, Massachusetts: National Bureau of Economic Research).

Lewis, Karen K., 1999, "Trying to Explain Home Bias in Equities and Consumption," Journal of Economic Literature, Vol. 37, No. 2, pp. 571-608.

Lewis, Karen K., 2000, “Why Do Stocks and Consumption Imply Such Different Gains from International Risk Sharing?” Journal of International Economics, Vol. 52, pp. 1-35.

Lucas, Robert E., Jr., 1987, Models of Business Cycles (Oxford: Blackwell Publishers).

Martin, Philippe, and Carol Ann Rogers, 2000, "Optimal Stabilization Policy in the Presence of Learning by Doing," Journal of Public Economic Theory, Vol. 2, No. 2, pp. 213-41.

Merton, Robert C., 1990, “The Financial System and Economic Performance," Journal of Financial Services Research, Vol. 4, No. 4, pp. 263-300.

Merton, Robert C., 2000, "Future Possibilities in Finance Theory and Finance Practice," Harvard Business School Working Paper No. 01-030.

Mundell, Robert A., 1961, “A Theory of Optimum Currency Areas,” American Economic Review, Vol. 51, pp. 509-517.

Obstfeld, Maurice, and Kenneth Rogoff, 1996, Foundations of International Macroeconomics, (Cambridge, Massachusetts: The MIT Press). 
Obstfeld, Maurice, 1994, "Evaluating Risky Consumption Paths: The Role of Intertemporal Substitutability," European Economic Review, Vol. 38, No. 7, pp. 1471-86.

Pallage, Stephane, and Michel Robe, 2003, "On the Welfare Cost of Economic Fluctuations in Developing Countries," International Economic Review, Vol. 44, No. 2.

Park, Yung Chul, and Yunjong Wang, 2005, "The Chiang Mai Initiative and Beyond," The World Economy, Vol. 28, No. 1, pp. 91-101.

Ramey, Garey, and Valerie A. Ramey, 1995, "Cross-Country Evidence on the Link between Volatility and Growth," American Economic Review, December, Vol. 85, No. 5, pp. $1138-51$.

Ravn, Morten O., 2001, "Consumption Dynamics and Real Exchange Rate," CEPR Discussion Papers 2940.

Reinhart, Carmen M., Kenneth S. Rogoff, and Miguel A. Savastano, 2003, "Debt Intolerance,” Brookings Papers on Economic Activity, Spring, No. 1, pp. 1-74.

Rose, Andrew, and Mark Spiegel, 2004, “A Gravity Model of Sovereign Lending: Trade, Default and Credit," Staff Papers, International Moneteray Fund, Vol. 51, pp. 50-63.

Shiller, Robert J., 1993, Macro Markets: Creating Institutions for Managing Society's Largest Economic Risks (Oxford: Oxford University Press, Clarendon Series).

Solnik, Bruno, 1974, "Why Not Diversify Internationally Rather Than Domestically?" Financial Analysts Journal, pp. 48-54.

Tesar, Linda L., 1993, “International risk-sharing and nontraded goods," Journal of International Economics, Vol. 35, pp. 69-89.

Van Wincoop, Eric, 1999, "How Big Are Potential Welfare Gains from International Risksharing?” Journal of International Economics, Vol. 47, pp. 109-135. 